Federal Reserve Bank of Minneapolis

Research Department Staff Report 390

April 2007

\title{
Time Consistent Monetary Policy with Endogenous Price Rigidity
}

\author{
Henry E. Siu* \\ University of British Columbia \\ and Federal Reserve Bank of Minneapolis
}

\begin{abstract}
I characterize time consistent equilibrium in an economy with price rigidity and an optimizing monetary authority operating under discretion. Firms have the option to increase their frequency of price change, at a cost, in response to higher inflation. Previous studies, which assume a constant degree of price rigidity across inflation regimes, find two time consistent equilibria - one with low inflation, the other with high inflation. In contrast, when price rigidity is endogenous, the high inflation equilibrium ceases to exist. Hence, time consistent equilibrium is unique. This result depends on two features of the analysis: (1) a plausible quantitative specification of the fixed cost of price change, and (2) the presence of an arbitrarily small cost of inflation that is independent of price rigidity.
\end{abstract}

*Email: hankman@interchange.ubc.ca. I thank Stefania Albanesi, Roc Armenter, Larry Christiano, Wouter den Haan, Huberto Ennis, Allen Head, Paul Klein, Nooman Rebei, Victor Ríos-Rull, Andreas Schabert, Alex Wolman, workshop participants at the Bank of Canada, UBC, UT Austin, Washington, Columbia, the 2004 Vienna Macro Workshop, the 2004 CMSG Meeting, the 2005 SED Meeting, the 2005 NBER Summer Institute, and especially Mick Devereux, Francisco Gonzalez, and Ed Nosal for helpful discussion and comments. Research funding from the SSHRC is gratefully acknowledged. The views expressed herein are those of the author and not necessarily those of the Federal Reserve Bank of Minneapolis or the Federal Reserve System. 


\section{INTRODUCTION}

Central bank policy is best characterized as being set with discretion: monetary policymakers do not simply implement policy plans determined in the past. So while it is crucial to characterize optimal policy under commitment, it is equally important to understand what outcomes can arise when policymakers act with discretion. Recently, this issue has been studied in the context of dynamic general equilibrium models of the monetary transmission mechanism. These studies maintain two assumptions. The first is lack of commitment on the part of the benevolent policymaker. The second is that the degree of price rigidity is independent of the inflationary regime. In these economies, equilibria are generally not unique. Expectation traps arise in which equilibria associated with expectations of low or high inflation become self-fulfilling. ${ }^{1}$ Hence, these models rationalize the view that the experience of the U.S. during the 1970s was due to a high inflation expectation trap.

Using the methods of Chari and Kehoe (1990), Chari et al. (1998) demonstrate this multiplicity in a sticky price model in which agents play trigger strategies (see also Barro and Gordon, 1983, Section IV). An important shortcoming, however, is that the play of trigger strategies admits many possible equilibria. ${ }^{2}$ Two recent papers - Albanesi et al. (2003) and King and Wolman (2004) - study discretionary policy when reputational mechanisms are ruled out. These papers show that expectation traps remain; that is, multiplicity does not rely on folk-theorem type reasoning, but is a germane feature of monetary discretion.

The intuition can be summarized as follows. Firms are monopolistic and set sticky prices. This provides an incentive for the monetary authority to generate unexpected inflation: since the output of sticky price firms is demand determined, unexpected inflation stimulates output and reduces the monopoly distortion. Costs of realized inflation generate a tradeoff, so that the monetary authority produces positive, but finite, inflation. Forward-looking

\footnotetext{
${ }^{1}$ For earlier analysis of the interaction between monetary discretion and a forward-looking private sector, see the seminal work of Kydland and Prescott (1977) and Barro and Gordon (1983). These studies describe linear-quadratic economies which display unique equilibrium.

${ }^{2}$ In a highly related framework, Ireland (1997) shows that the same model that predicts expectation traps predicts the first-best, commitment solution as an equilibrium outcome as well.
} 
firms account for this when setting prices. If firms expect low inflation to occur, they set accordingly low prices. If firms expect high inflation, they set high prices. Accommodation by the monetary authority validates private sector expectations. Hence, accommodation the hallmark of policy discretion - generates the possibility of multiple equilibria.

A problem with this reasoning is that it relies heavily on the degree of price rigidity being exogenous. With sticky prices, a firm's future price is simply not permitted to adjust for inflation that happens between now and then. Expectations of high inflation lead firms to set high prices now, thus compelling the monetary authority to deliver on those expectations. While assuming exogenously rigid prices is fruitful for monetary business cycle analysis, it seems problematic in formulating an explanation for high inflation episodes. This is particularly true since the assumption is central to generating high inflation.

I consider an economy in which the degree of price rigidity is endogenous. The objective is to determine the robustness of the expectation trap result in such a model, absent an appeal to reputational mechanisms. In the face of high inflation, firms can choose to incur a fixed cost to increase their frequency of price change. When the degree of price rigidity is allowed to adjust, the high inflation equilibrium ceases to exist. Time consistent equilibrium is unique. ${ }^{3}$ This result depends on: (1) a quantitatively reasonable specification of the fixed cost of price change, and (2) the presence of an arbitrarily small welfare cost of realized inflation that is independent of rigid prices.

I show this in two steps. First, I consider a 'simplified' model in which realized inflation is costly only when prices are sticky, so that only feature (1) is operational. Two time consistent equilibria exist, one with low inflation, the other with high inflation. For reasonable specifications of the fixed cost of price change, the high inflation equilibrium displays full price flexibility. With full flexibility, the cost-benefit trade-off in inflation disappears and the monetary authority is indifferent across inflation outcomes. Next, I introduce feature (2), a cost of inflation that is present regardless of whether prices are sticky or flexible.

\footnotetext{
${ }^{3}$ Ireland (2000) shows how multiplicity in the class of models considered by Ireland (1997) and Chari et al. (1998) can be eliminated by relaxing the assumption of rational expectations. For a critical assessment of expectation traps closer in spirit to that considered here, see Barseghyan and Di Cecio (2007).
} 
This breaks the monetary authority's indifference at full price flexibility. Thus, the high inflation equilibrium is eliminated in quantitatively relevant versions of the model, so that time consistent equilibrium is unique.

Section 2 presents the simplified model, and Section 3 characterizes equilibrium for arbitrary monetary policy. Section 4 details the crucial strategic complementarity in firms' pricing decisions that is the source of multiplicity, and how this depends on the specification of policy. Sections 5 and 6 characterize Markov perfect equilibrium in which the discretionary monetary authority maximizes private sector welfare. Section 7 discusses the perturbation of the model that eliminates the high inflation equilibrium and discusses robustness of the result. Section 8 concludes.

\section{THE MODEL}

Consider an infinite horizon economy populated by: a representative final good firm; a continuum of monopolistically competitive intermediate good firms; a representative household; and a discretionary monetary authority. Sticky prices among intermediate good firms admit non-neutral effects of monetary policy.

Specifically, firms make a pricing decision every second period; half of firms do so in odd periods, the other half in even, so that pricing decisions are staggered. This friction generates the welfare trade-off in inflation for the monetary authority (hereafter MA). Unexpected inflation erodes the real value of sticky prices, reducing the monopoly distortion. With staggered pricing, realized inflation distorts relative prices, generating misallocation of resources across firms. The MA must balance the marginal benefit of inflation, from the erosion of the monopoly distortion, with the marginal cost, from the exacerbation of the relative price distortion. To introduce endogenous price rigidity, a firm's pricing decision is modeled as having two dimensions: the price(s) to charge and the frequency of price change. I elaborate on this below.

Timing within a period is illustrated in Figure 1. First, the MA chooses the growth rate of the money stock; after observing this, private sector decisions are made. At the 
beginning of a period, the state observed by the MA is denoted $s \in \sigma$, which I call the MA state. To illustrate the mechanisms generating multiplicity or uniqueness as clearly as possible, reputational mechanisms are explicitly ruled out. ${ }^{4}$ Attention is restricted to the play of Markov strategies, so that $s$ contains only payoff relevant information. Since firms make pricing decisions every second period, the oldest information inherited by the MA at any point in time is one period old. Hence, $s=(\bar{p}, z)$, where $z \equiv z_{t-1}$ is the fraction of firms making pricing decisions in the previous period that chose to set prices on a periodby-period basis; $\bar{p} \equiv \bar{P}_{t-1} / M_{t-1}$ is the normalized price set by the $(1-z)$ firms that chose to set a two-period price. After observing $s$, the MA chooses a gross money growth rate, $X$. That is, if $M_{t}$ is the money stock at date $t, X_{t}=M_{t} / M_{t-1}$.

Private sector decisions are made after observing $(s, X)$. Call $(s, X)$ the private sector or PS state. Among these decisions are choices for $s^{\prime}=\left(\bar{p}^{\prime}, z^{\prime}\right)$. Since private sector agents make intertemporal decisions, they must have beliefs about how policy is chosen in the future. Since the MA acts after observing $s$, these beliefs are summarized as a money growth rule or policy rule, $\chi():. \sigma \rightarrow \mathcal{R}_{+}$.

\subsection{Final Good Production}

Final good firms are perfectly competitive and produce output using intermediate goods as input. Final goods are consumed by households. The representative firm's problem is:

$$
\max _{\left\{y_{i}\right\}} P\left[\int_{0}^{1} y_{i}^{(\lambda-1) / \lambda} d i\right]^{\lambda /(\lambda-1)}-\int_{0}^{1} P_{i} y_{i} d i, \quad \lambda>1 .
$$

Here, $P$ is the price of final output; $P_{i}$ is the price of intermediate input $i \in[0,1]$; and $\lambda$ is the elasticity of substitution across goods. The first-order necessary condition (FONC) for this problem states the familiar 'demand as a function of relative price' condition:

$$
y_{i}=\left(\frac{P}{P_{i}}\right)^{\lambda} y, \quad y \equiv\left[\int_{0}^{1} y_{i}^{(\lambda-1) / \lambda} d i\right]^{\lambda /(\lambda-1)} .
$$

\footnotetext{
${ }^{4}$ Discussion regarding the extension of results to other equilibrium concepts such as sustainable equilibrium is contained in Section 8.
} 


\subsection{Intermediate Good Production}

Intermediate good firms produce goods using labor according to $y_{i}=h_{i}$. Labor is hired at the competitive wage $W$. Linearity in production implies that the nominal wage is exactly the firm's nominal marginal cost.

Price rigidity is introduced via the decision-making constraints of these firms. Suppose firms have only one option in their pricing decision: choose a single price to charge in the current and following period after observing the PS state, $(s, X)$. This is the standard, twoperiod Taylor (1980) form of price stickiness found in the monetary business cycle literature (see, for example, the textbook treatment of Romer, 2001, ch. 6), and is the specification used in King and Wolman (2004), hereafter KW.

In this paper, a firm making its pricing decision has two options: (a) be sticky, and choose a single price after observing $(s, X)$ for the current and following period; or (b) be flexible, and choose one price for the current period after observing $(s, X)$, and another price in the next period after observing $\left(s^{\prime}, X^{\prime}\right)$. Choosing option (b) requires paying a fixed cost. $^{5}$ This fixed cost corresponds to the incremental decision-making and implementation cost of one additional price change within the same duration of time. Firms choose their frequency of price change in response to expected inflation. This specification is chosen for the sake of expositional clarity. The key results are robust to and, in fact, strengthened in more elaborate specifications of endogenous price rigidity, such as those used in the state-dependent pricing literature; see Section 7 for discussion.

2.2.1. Sticky prices If a firm chooses to set a sticky price, it chooses a single price, $\bar{P}^{\prime}$, to maximize two-period discounted profits:

$$
\bar{\Upsilon} \equiv \max _{\overline{P^{\prime}}}\left[\alpha\left(P^{\lambda} \bar{P}^{\prime 1-\lambda} y-W P^{\lambda} \bar{P}^{\prime-\lambda} y\right)+\beta \alpha^{\prime}\left(P^{\prime \lambda} \bar{P}^{\prime 1-\lambda} y^{\prime}-W^{\prime} P^{\prime \lambda} \bar{P}^{\prime-\lambda} y^{\prime}\right)\right]
$$

where primes $\left({ }^{\prime}\right)$ denote one-period-ahead variables. Here, the final good firm's demand function has been substituted in, and $\alpha$ is the marginal value of current profit to the

\footnotetext{
${ }^{5}$ This is equivalent to assuming that firms pay a fixed cost for every price change, but are assumed to do so at least every second period.
} 
representative household. I denote the sticky price set today with a prime since this is the price (after normalization) that is inherited in the MA state, $s^{\prime}$, in the following period. In a symmetric equilibrium, all sticky price firms charge the same two-period price:

$$
\bar{P}^{\prime}=\hat{\lambda}\left(\frac{\alpha P^{\lambda} y W+\beta \alpha^{\prime} P^{\prime \lambda} y^{\prime} W^{\prime}}{\alpha P^{\lambda} y+\beta \alpha^{\prime} P^{\prime \lambda} y^{\prime}}\right), \quad \hat{\lambda}=\frac{\lambda}{\lambda-1},
$$

which is a markup, $\hat{\lambda}$, over the weighted sum of current and future marginal cost.

2.2.2. Flexible prices If a firm chooses to be flexible, it chooses a price to charge today, $\tilde{P}$, and a price to charge tomorrow, $\tilde{P}^{\prime}$, according to:

$$
\tilde{P}=\hat{\lambda} W, \quad \tilde{P}^{\prime}=\hat{\lambda} W^{\prime}
$$

Since these prices are chosen after observing the MA's action in each period, they are set optimally as a markup over observed marginal cost.

To set flexible prices, a firm must pay a fixed cost, $\phi$. This represents the units of labor it will expend to set a new price after observing $M^{\prime}$. A firm will choose option (b) over option (a) if the difference in discounted two-period profits is greater than the fixed cost. That is, a firm with fixed cost $\phi_{i}$ will choose to be flexible if:

$$
\alpha \tilde{\Pi}+\beta \alpha^{\prime}\left[\tilde{\Pi}^{\prime}-W^{\prime} \phi_{i}\right] \geq \bar{\Upsilon}
$$

where $\tilde{\Pi}=(\tilde{P}-W)(P / \tilde{P})^{\lambda} y$ denotes optimized one-period profit. Call this condition the cut-off condition.

The CDF for the fixed cost is denoted $\mathcal{F}(\phi)$. A goal of this paper is to show that for plausible magnitudes of $\phi$, firms choose to be flexible in high inflation equilibria. Hence, the exact specification of the distribution is not important, but simply that the support is bounded with a maximal value, $\phi_{\max } \cdot{ }^{6}$ Denote the value of the fixed cost that satisfies the cut-off condition with equality as $\phi^{*}$. All firms with $\phi_{i} \leq \phi^{*}$ choose to set flexible prices,

\footnotetext{
${ }^{6}$ Indeed, the distribution can be degenerate at $\phi_{\max }$ without altering any of the key results. Allowing for a smooth CDF aids both in exposition (since it eliminates discrete jumps from full rigidity to full flexibility) and in numerical computation of equilibrium.
} 
while all others set sticky prices. The fraction of firms currently making pricing decisions that choose flexibility is $z^{\prime}=\mathcal{F}\left(\phi^{*}\right)$, again, denoted with a prime since this is the fraction of flexible price firms inherited by the MA in the next period. If the cut-off condition holds with inequality at $\phi_{\max }$, then $z^{\prime}=1$.

\subsection{Households}

Households value consumption $(c)$ and labor $(h)$ according to:

$$
\sum_{t} \beta^{t}\left[\log c_{t}-\psi h_{t}\right], \quad 0<\beta<1, \psi>0
$$

The household faces two sequences of constraints. The first is the flow budget constraint:

$$
M_{t}+B_{t} \leq R_{t-1} B_{t-1}+M_{t-1}-P_{t-1} c_{t-1}+\left(1+\theta_{t-1}\right)\left(W_{t-1} h_{t-1}+\int_{0}^{1} \Pi_{i, t-1} d i\right)+T_{t} .
$$

This is relevant during securities trading in each period $t$. Here, $B_{t}$ is nominal bond holdings that pay a gross return of $R_{t}$ upon maturity at date $t+1 ; M_{t}$ is the value of money holdings; $P_{t}$ is the consumption good price; $W_{t}$ is the nominal wage rate; $\Pi_{i, t}$ are nominal profits from firm $i \in[0,1]$; and $T_{t}$ is a lump-sum transfer from the MA. Finally, $\theta_{t}$ is a subsidy to production income.

After securities trading, households interact with firms in the goods and labor markets. The household supplies labor at the wage $W_{t}$ and buys consumption at the price $P_{t}$. Consumption purchases are subject to a cash-in-advance constraint:

$$
M_{t} \geq P_{t} c_{t}, \quad \forall t
$$

The household's intertemporal FONC is:

$$
\frac{1}{P c}=\beta R \frac{1}{P^{\prime} c^{\prime}}
$$

In equilibrium it must be that $R \geq 1$, so that the household does not find it profitable to buy money and sell bonds. As a result, the cash-in-advance constraint holds with equality. Substituting this into the FONC delivers:

$$
\chi\left(s^{\prime}\right)=\frac{M^{\prime}}{M}=\beta R .
$$


In equilibrium, the rate of nominal interest reflects the expected rate of money growth relative to time preference.

The household's intratemporal FONC is:

$$
\frac{1}{c}\left(\frac{1+\theta}{R}\right) \frac{W}{P}=\psi
$$

Absent the subsidy $(\theta=0)$, a non-zero nominal interest rate drives a wedge between the real wage and the marginal rate of substitution in consumption and labor. This distortion represents the fact that expected future inflation erodes the return to current labor effort in cash-in-advance models (see Cooley and Hansen, 1989).

I set $\theta=R-1$ to eliminate this distortion. I do this for two reasons. First, the cost of expected future inflation cannot be influenced by the current MA; eliminating this makes it clear that it is the welfare trade-off between the current benefit of unexpected inflation and the current cost of realized inflation that characterizes monetary discretion. Second, setting $\theta=R-1$ and using the cash-in-advance constraint, the intratemporal FONC becomes:

$$
W=\psi M
$$

In equilibrium, the growth rate of the nominal wage between any two periods, $t$ and $t+1$, is determined by the money growth rate between $t$ and $t+1$. This ensures that across low and high inflation regimes, aggregate price level inflation is appropriately reflected in the growth rate of wages/marginal cost. ${ }^{7}$ Finally, with $\theta=R-1$, the marginal value of current profit is given by $\alpha=1 / P c$.

\subsection{Government Budget Constraint}

The budget constraint faced by the MA is:

$$
T_{t}=M_{t}-M_{t-1}-\theta_{t-1}\left(W_{t-1} h_{t-1}+\int_{0}^{1} \Pi_{i, t-1} d i\right), \quad \forall t .
$$

\footnotetext{
${ }^{7}$ This discussion makes clear that it would be inappropriate to consider 'real rigidities' (see, for example, Ball and Romer, 1991) in the current analysis. Such considerations typically manifest in equilibrium divergences between money growth and marginal cost growth that would be inappropriate for the study of perfectly anticipated, trend inflation.
} 
The lump-sum transfer to the household finances the money injection, net of the subsidy to production income. The MA does not issue or purchase nominal bonds, so these are in zero net supply.

\section{PRIVATE SECTOR EQUILIBRIUM}

Though ultimate interest is in characterizing Markov perfect equilibrium (MPE), I first define a private sector equilibrium (PSE) in which the MA's current action, $X$, and future policy, $\chi$, need not be welfare maximizing. In the definition, lowercase variables denote nominal variables chosen in the current period normalized by the current money stock, e.g., $p \equiv P / M, \bar{p}^{\prime} \equiv \bar{P}^{\prime} / M, \tilde{p} \equiv \tilde{P} / M$, etc. I do this since all equilibria are neutral in the usual sense: if the initial money stock is doubled, a PSE exists in which all real allocations are identical and only nominal variables are doubled.

Definition 1 Given beliefs (a policy rule) $\chi$, for all PS states $(s, X)$, a private sector equilibrium is a set of allocation rules $\{c(s, X ; \chi), h(s, X ; \chi)\}$, pricing rules $\left\{\bar{p}^{\prime}(s, X ; \chi)\right.$, $\left.\tilde{p}(s, X ; \chi), z^{\prime}(s, X ; \chi)\right\}$, and prices $\{R(s, X ; \chi), p(s, X ; \chi)\}$ such that: households are optimizing, prices are set optimally, $z^{\prime}(s, X ; \chi)$ satisfies the cut-off condition, the goods, labor, and bond markets clear, and $R(s, X ; \chi) \geq 1$.

By Walras' Law, the money market clears.

In the rest of this section, I provide a more compact characterization of PSE. First, the household's intratemporal FONC states that the normalized wage is constant, $w=\psi$. Hence, the normalized flexible price is also constant, $\tilde{p}=\hat{\lambda} \psi$.

Final good firm maximization generates the normalized price level equation:

$$
p(s, X ; \chi)=\left\{\frac{1}{2}\left[(1-z)\left(\frac{\bar{p}}{X}\right)^{1-\lambda}+\left(1-z^{\prime}\right) \bar{p}^{\prime 1-\lambda}+\left(z+z^{\prime}\right)(\hat{\lambda} \psi)^{1-\lambda}\right]\right\}^{\frac{1}{1-\lambda}}
$$

where $z^{\prime}=z^{\prime}(s, X ; \chi)$ and $\bar{p}^{\prime}=\bar{p}^{\prime}(s, X ; \chi)$. From the cash-in-advance constraint:

$$
c(s, X ; \chi)=1 / p(s, X ; \chi) .
$$


The labor market clearing condition is:

$$
\begin{aligned}
h(s, X ; \chi)=\frac{p^{\lambda-1}}{2}\left[(1-z)\left(\frac{\bar{p}}{X}\right)^{-\lambda}+\left(1-z^{\prime}\right) \bar{p}^{\prime-\lambda}+\left(z+z^{\prime}\right)(\hat{\lambda} \psi)^{-\lambda}\right]+ & \\
& \frac{1}{2} \int_{0}^{\mathcal{F}^{-1}(z)} \phi d F(\phi),
\end{aligned}
$$

where $p=p(s, X ; \chi)$. Finally, the intertemporal FONC bounds the set of feasible PSE money growth rules; $R(s, X ; \chi)=\chi\left(s^{\prime}\right) / \beta$, so that $\chi(s) \geq \beta$ for all $s$.

Hence, equilibrium $p(),. c(),. h($.$) , and R($.$) are determined residually from \bar{p}^{\prime}($.$) and$ $z^{\prime}($.$) . These are determined as follows. The FONC for sticky price setting implies that:$

$$
\bar{p}^{\prime}=\hat{\lambda} \psi\left(\frac{p^{\lambda-1}+\beta p^{\prime \lambda-1} \chi\left(s^{\prime}\right)^{\lambda}}{p^{\lambda-1}+\beta p^{\prime \lambda-1} \chi\left(s^{\prime}\right)^{\lambda-1}}\right),
$$

where $p^{\prime}=p\left(s^{\prime}, \chi\left(s^{\prime}\right) ; \chi\right)$. Finally, the cut-off condition states that $z^{\prime}$ satisfies:

$$
\begin{aligned}
\frac{p^{\lambda-1}}{\hat{\lambda}^{\lambda} \psi^{\lambda}}(\hat{\lambda}-1) \psi+\beta\left[\frac{p^{\prime \lambda-1}}{\hat{\lambda}^{\lambda} \psi^{\lambda}}(\hat{\lambda}-1)-\mathcal{F}^{-1}\left(z^{\prime}\right)\right] \psi \geq \\
\frac{p^{\lambda-1}}{\bar{p}^{\prime \lambda}}\left(\bar{p}^{\prime}-\psi\right)+\beta p^{\prime \lambda-1}\left(\frac{\chi\left(s^{\prime}\right)}{\bar{p}^{\prime}}\right)^{\lambda}\left(\frac{\bar{p}^{\prime}}{\chi\left(s^{\prime}\right)}-\psi\right) .
\end{aligned}
$$

This holds with strict equality whenever $z^{\prime}<1$, and with weak inequality whenever $z^{\prime}=1$. Conditions (4) and (5) characterize PSE $\bar{p}^{\prime}$ and $z^{\prime}$. Remaining PSE objects are determined as described above. This result is summarized as follows:

Proposition 2 Given beliefs $\chi$, a PSE is characterized as decision rules, $\bar{p}^{\prime} \equiv \mathrm{P}(s, X ; \chi)$ and $z^{\prime} \equiv \mathrm{Z}(s, X ; \chi)$, such that for all $(s, X)$, equations (4) and (5) are satisfied.

The equilibrium conditions make it clear that the only payoff relevant variables inherited by the current MA are the previous period's pricing decisions. Hence, when attention is turned to MPE, the MA state is $s=(\bar{p}, z)$. Moreover, when the MA inherits full price flexibility, current money growth is neutral. The intuition for this is obvious. With no inherited price stickiness, current money growth has no effect on the monopoly distortion or the relative price distortion, since this influence requires the presence of sticky prices. ${ }^{8}$

\footnotetext{
${ }^{8}$ To see this, note that when $z=1$, current money growth, $X$, has no direct influence on the normalized price level, $p$ (see equation (1)). But since $X$ enters the decision rules, $\mathrm{P}$ and $\mathrm{Z}$, only indirectly via $p$ (see
} 


\section{MULTIPLICITY OF EQUILIBRIUM}

Having characterized PSE, it is possible to illustrate the potential for multiple equilibria. Multiplicity of PSE stems from a strategic complementarity across intermediate good firms' pricing decisions for particular monetary policy rules. Monetary policy satisfies these conditions whenever it is sufficiently accommodative of private sector expectations. It is this multiplicity of PSE that translates into multiple MPE when the MA is maximizing. ${ }^{9}$

\subsection{Strategic Complementarity in Price Setting}

This strategic complementarity is first illustrated by KW, and I discuss it here for completeness. To do so, it is easiest to work with their model, where increasing the frequency of price change is infinitely costly. All firms act as sticky price firms in PSE. The MA and PS states are reduced to $s=\bar{p}$ and $(s, X)=(\bar{p}, X)$, respectively.

Following KW, I interpret the sticky price firm's FONC, (4), as the best response function for an individual firm: given $(\bar{p}, X)$ and $\chi$, this maps out the optimal price for firm $i, \bar{p}_{i}^{\prime}$, as a function of all other price-setting firms' price, $\bar{p}_{j}^{\prime}, \forall j \in[0,1]$ and $j \neq i$. Specifically:

$$
\bar{p}_{i}^{\prime} \equiv f\left(\bar{p}_{j}^{\prime} ; \bar{p}, X ; \chi\right)=\hat{\lambda}\left[(1-\gamma) \psi+\gamma \chi\left(\bar{p}_{j}^{\prime}\right) \psi\right]
$$

Firm $i$ 's optimal price is a markup over a weighted average of current and future marginal cost, where the relative weight on future marginal cost is given by:

$$
\gamma \equiv \gamma\left(\bar{p}_{j}^{\prime} ; \bar{p}, X ; \chi\right)=\frac{\beta p^{\prime \lambda-1} \chi\left(\bar{p}_{j}^{\prime}\right)^{\lambda-1}}{p^{\lambda-1}+\beta p^{\prime \lambda-1} \chi\left(\bar{p}_{j}^{\prime}\right)^{\lambda-1}} .
$$

Here, $p$ is given by equation (1) with $z=z^{\prime}=0$ and $\bar{p}^{\prime}=\bar{p}_{j}^{\prime}$, and $p^{\prime}$ and (implicitly) $\bar{p}^{\prime \prime}$ are given by the one-period-ahead versions of equations (1) and (4), respectively, with $z^{\prime}=z^{\prime \prime}=0$ and $\left(s^{\prime}, X^{\prime}\right)=\left(\bar{p}_{j}^{\prime}, \chi\left(\bar{p}_{j}^{\prime}\right)\right)$. PSE requires $\bar{p}_{i}^{\prime}=\bar{p}_{j}^{\prime}$.

equations (4) and (5)), there is no influence of current money growth on $\bar{p}^{\prime}$ and $z^{\prime}$ when $z=1$. Hence, there is no effect on consumption or hours worked (see equations (2) and (3)).

${ }^{9}$ This differs from the multiplicity result of Albanesi et al. (2003), where given policy, PSE is unique. Instead, their framework generates multiple solutions to the MA's problem that are rationalized by expectations. See their paper and KW for discussion. 
If $\partial f / \partial \bar{p}_{j}^{\prime}>0$, there exists strategic complementarity: the higher is the price set by other firms, the higher is the optimal price for any individual firm (see Cooper and John, 1988). If this complementarity is sufficiently strong, there may be multiple equilibria. Whether this is the case depends wholly on the policy rule, $\chi$.

As a benchmark, consider $\chi(\bar{p}) \equiv 1$, the case in which the MA always delivers zero money growth. This corresponds to the first-best policy achieved under commitment. ${ }^{10}$ Since money growth does not respond to price setting, marginal cost is constant across periods $\left(W^{\prime} / W=\chi(\bar{p})=1\right)$. Regardless of the price set by other firms, an individual firm's optimal price is the static markup rule; the best response function reduces to $\bar{p}_{i}^{\prime}=\hat{\lambda} \psi$. With zero money growth there is no complementarity. This is displayed in Figure 2.

Now consider the case when money growth is an increasing, linear function of prices, $\chi(\bar{p})=a_{0}+a_{1} \bar{p}, a_{1}>0$. As firms set higher prices, $\bar{p}_{j}^{\prime}$, future marginal cost, $\chi\left(\bar{p}_{j}^{\prime}\right) \psi$, rises. Moreover, as $\chi$ rises, $\gamma \rightarrow 1$, so that the weight on future marginal cost rises too. The optimal price for a firm is increasing in the price set by others. Complementarity exists because the policy rule responds positively to - or accommodates - the pricing of firms.

I illustrate this for $\chi(\bar{p})=0.302 \times \bar{p}$ in Figure $3 .{ }^{11}$ Consider either the solid or dashed line. The best response function first crosses the $45^{\circ}$ line from above. As $\bar{p}_{j}^{\prime}$ increases so too does the slope, and there is a second crossing of the $45^{\circ}$ line from below. Because $\gamma \rightarrow 1$ as $\bar{p}_{j}^{\prime}$ rises, and because $\partial \chi / \partial \bar{p}=a_{1}$ :

$$
\lim _{\bar{p}_{j}^{\prime} \rightarrow \infty} \partial f / \partial \bar{p}_{j}^{\prime}=\hat{\lambda} \psi a_{1}
$$

Hence, when the policy rule is linear, a necessary condition for multiplicity is that $\hat{\lambda} \psi a_{1}>1$. This is not sufficient since it is possible that the best response function, $f$, lies above the $45^{\circ}$ line so that no PSE exist, or one PSE exists (in the case of a tangency). When

\footnotetext{
${ }^{10}$ See King and Wolman (1999). The intuition is straightforward. 'Money demand' distortions associated with inflation greater than the Friedman Rule are eliminated by the subsidy, $\theta$. With commitment, the MA has no influence on the monopoly distortion since inflation is perfectly anticipated. Hence, the only distortion affected by policy is the relative price distortion; this is eliminated with zero inflation.

${ }^{11}$ Here are some numerical details with additional discussion contained in Appendix A: $\beta=0.98, \lambda=11$, and $\psi$ is set so that $h_{s s}=0.3$ in the zero-inflation steady state.
} 
multiple crossings exist, there are exactly two of them: an optimistic equilibrium with current expectations coordinated on low inflation (and actions coordinated on low price setting), and a pessimistic equilibrium with expectations of high inflation.

In the case of multiplicity, the best response function depends on how expectations are coordinated in the future. This is because the relative weight, $\gamma$, depends on the sticky price set next period, $\bar{p}^{\prime \prime} ; \bar{p}^{\prime \prime}$ in turn depends on $\bar{p}^{\prime \prime \prime}$, and so on. Private sector agents must have beliefs regarding equilibrium selection today and in all subsequent periods.

This is illustrated in Figure 3 for the case of perfect foresight. This amounts to agents understanding which equilibrium will prevail in every period. The solid line displays the best response function when expectations are coordinated on low inflation in all future periods. If agents also expect low inflation today, this results in the crossing marked with the diamond; the second, unmarked crossing corresponds to the case when agents expect high inflation today. The dashed line displays the best response function when agents expect high inflation in all subsequent periods; the crossing marked with the square represents a PSE when expectations are coordinated on high inflation today.

Finally, Figure 4 illustrates that the exact number of crossings depends on the shape of the policy rule $\chi$. Here, $\partial^{2} \chi / \partial \bar{p}^{2}$ is initially positive, but beyond an inflection point is negative. As a result, the number of crossings is three. Figure 4 displays the best response function when future expectations are coordinated on the lowest inflation equilibrium.

\subsection{Discussion}

Before proceeding, I provide a few comments on the source of complementarity. First, when attention is turned to monetary discretion, the policy rule will be an increasing function of the normalized sticky price: a benevolent MA finds it optimal to accommodate the private sector's expectations and pricing decisions.

Second, I contrast the strategic complementarity highlighted here and that discussed in Ball and Romer (1991). There are three key differences. First, in Ball and Romer the complementarity arises from the endogenous decision of firms to alter prices in a state- 
contingent manner. Here, the complementarity operates through the exogenously rigid two-period Taylor price. Second, Ball and Romer's complementarity operates through a feedback of current price setting, through current marginal cost, into the pricing decision of firms. Here, current (normalized) marginal cost is pinned down as $\psi$, but future marginal cost, $\chi\left(\bar{p}^{\prime}\right) \psi$, responds via the policy rule, $\chi$. The last and most important difference is that in Ball and Romer, the feedback is due to real rigidity in marginal cost. Here, firms' expectations about other firms' actions and - crucially - the accommodative monetary policy response to those actions, feeds back into pricing decisions.

Finally, an important element to the complementarity is the effect of price setting on the relative weight placed on future marginal cost. As firms raise prices, future marginal cost rises and an individual firm cares more about the future in price setting. This is because the firm's profit function is asymmetric across having a relative price that is too high versus one that is too low. This asymmetry is discussed in detail in Devereux and Siu (2007), and can be understood through the following thought experiment.

Suppose future money growth, $\chi\left(\bar{p}_{j}^{\prime}\right)$, is high. Further, suppose firm $i$ must decide between pricing as a markup over current marginal cost, $\bar{p}_{i}^{\prime}=\hat{\lambda} \psi$, or future marginal cost, $\bar{p}_{i}^{\prime}=\hat{\lambda} \chi\left(\bar{p}_{j}^{\prime}\right) \psi$. In either case, it earns statically-optimal profit in one of the two periods.

By choosing the latter price, the firm earns optimal profit in the second period, but its current price is high relative to prices set in the previous period. As a result, the firm's first period demand and profit is low, but bounded above zero. Now suppose the firm prices to current marginal cost: it earns optimal profits in the first period, but its future relative price is low. This implies that the firm's second period demand will be high, in the same period when its profit margin is negative (at least for sufficiently high marginal cost growth).

Hence, the firm prefers to set a price that is too high relative to one that is too low; the firm sacrifices current profit to ensure non-negative profit in the future. It is this relative price effect on a firm's demand that makes the weight, $\gamma$, increasing in $\bar{p}^{\prime}{ }^{12}$ As long as

\footnotetext{
${ }^{12}$ This example is extreme since any firm, given the opportunity, would not meet demand at a negative profit margin. However, the intuition holds for any positive value of money growth. Again, see Devereux and Siu (2007) for discussion.
} 
the policy rule, $\chi$, is increasing in $\bar{p}$, the asymmetry in profit strengthens the strategic complementarity in price-setting behavior.

\subsection{The Case with Endogenous Price Rigidity}

With exogenous price rigidity the only action firms can take to guard against high future inflation is to set a high price now. However, it is plausible that firms take other defensive actions when faced with high inflation. One is to reset prices more often. Here, I consider a simple example to show that the fraction of firms choosing flexibility increases with future inflation.

Let the MA's policy rule be $\chi(\bar{p}, z)=0.302 \times \bar{p}$, and let the fixed cost of price change be uniformly distributed, $\mathcal{F}(\phi)=U\left[0, \phi_{\max }\right]$. For different values of the two-period price, $\bar{p}_{j}^{\prime}$, I use the cut-off condition (5) to determine the fraction of firms that prefer flexibility, $z^{\prime}$, as opposed to charging $\bar{p}_{j}^{\prime}$. The FONC (4) is used to determine the best response sticky price, $\bar{p}_{i}^{\prime}$. Figure 5 plots $\bar{p}_{i}^{\prime}$ and $z^{\prime}$ for two values of $\phi_{\max }$ : the first column sets the maximal fixed cost to $20 \%$ of per-period firm revenue in the zero-inflation steady state, and the second column sets this to 10\%. For simplicity, I plot only the case when agents expect low inflation in future periods. Remaining parameter values are as specified in Subsection 4.1, and details on computation are in Appendix A.

Allowing for endogenous price rigidity does not qualitatively change the best response function. There are two PSE. The first features expectations of low inflation and a small degree of price flexibility, the second with expectations of high inflation and greater flexibility. As $\phi_{\max }$ falls, an increasing number of firms choose to be flexible for given future inflation, as shown in the second column. For sufficiently high values of inflation, all firms choose flexibility, $z^{\prime}=1$. At this point the best response function ceases to be 'relevant' since no firms actually set sticky prices. ${ }^{13}$

\footnotetext{
${ }^{13}$ This makes interpretation of the policy rule, $\chi(\bar{p})$, in this example somewhat difficult. This is no longer a problem when I consider a maximizing policy authority whose rule, $\chi(\bar{p}, z)$, is also a function of the fraction of flexible price firms. See Section 6.
} 


\section{A MAXIMIZING MONETARY AUTHORITY}

The MA's objective is to maximize the present discounted value of household utility from the current period forward through the choice of current money growth, $X$. The MA takes past decisions and its future incarnation's policy rule, $\chi$, as given and beyond its control. This is the expression of the time-consistency problem as articulated by Kydland and Prescott (1977): the current MA is unable to compel its future self to appropriately account for the effect of its policy on current private sector expectations and decisions.

Here, the time-consistency problem takes on an added dimension. Private sector behavior depends on expectations of future policy, given by $\chi$. But certain policy rules admit multiple PSE. This implies that private sector agents must have beliefs regarding the coordination of expectations. The current MA must take this coordination of expectations as given. Hence, the MA is 'trapped' by inflation expectations in its policy problem.

To emphasize this, I introduce an indicator variable, $\zeta$, that summarizes the coordination of expectations across PSE. ${ }^{14}$ Private sector decision rules are now indexed by $\zeta$ and $\chi$ to highlight the dependence of optimal behavior on both expectations coordination and expectations of future policy.

The MA's problem can be stated as:

$$
\max _{X}\left[U(s, X ; \chi, \zeta)+\beta U\left(s^{\prime}, \chi\left(s^{\prime}\right) ; \chi, \zeta\right)+\beta^{2} U\left(s^{\prime \prime}, \chi\left(s^{\prime \prime}\right) ; \chi, \zeta\right)+\ldots\right], \quad \forall s \in \sigma
$$

taking as given $\chi$ and $\zeta$. Here, $s=(\bar{p}, z), U(s, X ; \chi, \zeta)=\log c(s, X ; \chi, \zeta)-\psi h(s, X ; \chi, \zeta)$, $s^{\prime}=(\mathrm{P}(s, X ; \chi, \zeta), \mathrm{Z}(s, X ; \chi, \zeta))$, and so on; $\mathrm{P}($.$) and \mathrm{Z}($.$) are defined by equations (4)$ and (5); and $c($.$) and h($.$) are defined by equations (2) and (3). An MPE can be defined$ as a PSE and a policy rule, $\chi: \sigma \rightarrow[\beta,+\infty)$, that solves the MA's problem.

Since the MA takes the coordination of expectations as given, the MPE policy rule, $\chi(s ; \zeta)$, is also indexed by $\zeta$. This dependence of optimal policy on $\zeta$ is the manifestation

\footnotetext{
${ }^{14}$ For instance, in the case of perfect foresight, $\zeta$ could be an entire time-indexed sequence indicating which equilibrium prevails in each period. In the case of stationary sunspot equilibrium, $\zeta$ could indicate the probability distribution under which equilibria occur (with expectation operators introduced to the notation in the appropriate manner).
} 
of the expectation trap.

Here, I present an alternative definition of MPE due to Klein et al. (2006), which is useful for computation of equilibrium. ${ }^{15}$

Definition 3 Given $\zeta$, a Markov perfect equilibrium consists of a value function, $V$; decision rules, $\mathrm{P}$ and $\mathrm{Z}$; and a policy rule, $\chi$, such that for all $s=(\bar{p}, z) \in \sigma$ :

- given $\chi(s ; \zeta), \mathrm{P}(s, X ; \chi, \zeta)$ and $\mathrm{Z}(s, X ; \chi, \zeta)$ are the PSE decision rules characterized in Proposition 2;

- given $\mathrm{P}(s, X ; \chi, \zeta), \mathrm{Z}(s, X ; \chi, \zeta)$, and $V(s ; \zeta)$ :

$$
\chi(s ; \zeta) \in \underset{X}{\operatorname{argmax}}[U(s, X ; \chi, \zeta)+\beta V(\mathrm{P}(s, X ; \chi, \zeta), \mathrm{Z}(s, X ; \chi, \zeta) ; \zeta)]
$$

- given $\mathrm{P}(s, X ; \chi, \zeta), \mathrm{Z}(s, X ; \chi, \zeta)$, and $\chi(s ; \zeta)$ :

$$
V(s ; \zeta)=U(s, \chi(s ; \zeta) ; \chi, \zeta)+\beta V(\mathrm{P}(s, \chi(s) ; \chi, \zeta), \mathrm{Z}(s, \chi(s) ; \chi, \zeta) ; \zeta)
$$

To conserve on notation, I do not index $V$ by $\chi$, since this dependence is obvious; the value function is constructed using private sector decision rules which: (i) depend on $\chi$, and (ii) take the current period money growth rate as $\chi(s, \zeta)$. This last restriction is correct, since the value function is used by the current MA in evaluating future welfare, taking future policy as given by $\chi$. Definition 3 concisely captures the notion of time consistency: the policy rule attributed to the choice of money growth by the future MA coincides with the optimizing choice of current money growth for all $s \in \sigma$, given $\zeta$.

\section{ANALYZING MARKOV PERFECT EQUILIBRIUM}

Here I study MPE in calibrated versions of the model. In Subsection 6.1, I consider the play of differentiable policy rules on the part of the MA. The first objective is to illustrate that two MPE exist. The second is to characterize the degree of price rigidity in the high

\footnotetext{
${ }^{15}$ For a related definition of time consistent equilibrium, see the appendix of Kydland and Prescott (1977).
} 
inflation equilibrium. Subsection 6.2 considers the case with policy rules discontinuous at full price flexibility, $z=1$.

I restrict attention to the case of perfect foresight. Stochastic equilibria in which expectations randomly fluctuate across periods of low and high inflation can be constructed. Since the emphasis of this paper is to show that the pessimistic equilibrium is fragile, I do not analyze this possibility. For much of the analysis, I focus on the case of constant expectations coordination, in which agents understand that either the optimistic or the pessimistic equilibrium occurs in all periods. In Subsection 6.1.2, I also discuss the case with deterministic fluctuations across low and high inflation periods.

The model parameterization is standard. I set $\beta=0.98$ to accord with a period length of six months and an annual risk-free real interest rate of $4 \%$. The demand elasticity of substitution, $\lambda$, determines the strength of the strategic complementarity. As in much of the sticky price literature, I choose $\lambda=11$ as a benchmark value. This implies a price-tomarginal-cost markup of $10 \%$ in the zero inflation steady state (see, e.g., Chari et al., 2000; KW; and Devereux and Siu, 2007). I also consider smaller values of $\lambda$ (higher markups) to capture the range of values used in the literature. ${ }^{16}$ The fraction of time spent in market activity in the zero inflation steady state is $h_{s s}=0.3$.

\subsection{Analysis of the Differentiable Case}

I first consider the play of differentiable policy rules in which:

$$
\chi(\bar{p}, 1 ; \zeta)=\lim _{z \rightarrow 1} \chi(\bar{p}, z ; \zeta), \quad \forall \bar{p}
$$

despite the fact that the MA is indifferent between all values of $X$ at full price flexibility. To make this operational, I solve for MPE by approximating the MA's policy rule by a tensor product of Chebychev polynomials, which is continuously differentiable by construction. I outline the algorithm developed to solve for MPE in Appendix B.

\footnotetext{
${ }^{16}$ For instance, $\lambda=4.33$ in Dotsey et al. (1999), and $\lambda=3.22$ in Christiano et al. (2005).
} 
6.1.1. Exogenous price rigidity When the fixed cost is infinitely large, no firm chooses to reset its price more frequently than once every two periods. Results from this version can be summarized as follows:

Proposition 4 With exogenous price rigidity, the MPE policy rule, $\chi(\bar{p})$, is proportional in $\bar{p}$. Hence, at most two locally isolated MPE exist: an optimistic equilibrium with low expected and realized inflation, and a pessimistic equilibrium with high inflation.

Discussion of this result is contained in $\mathrm{KW}$, in their characterization of a homogeneous money stock rule. The intuition is straightforward. From the PSE decision rules, (2) and (3), the direct effect of money growth on real outcomes is in direct proportion to the normalized preset price, $\bar{p}$. Moreover, $\bar{p}^{\prime}$ or $z^{\prime}$ depend on money growth only via its effect on $p$, where again, the effect is proportional to $\bar{p}$. As a result, optimal money growth, $\chi(\bar{p})$, is proportional to $\bar{p}$.

Given this linearity, Subsection 4.1 shows that (generically) the number of PSE is two. As a result, there are two MPE. In the steady state of the optimistic MPE (with expectations coordinated on low inflation in all periods), the inflation rate is $1.9 \%$ per period $(3.8 \%$ per year), while real output is $0.04 \%$ lower than in the first-best, zero inflation steady state. In the pessimistic MPE steady state, inflation is much higher at $13.8 \%$ per period, and output is $1.91 \%$ lower than with zero inflation. Hence, the pessimistic equilibrium can be interpreted as stagflation relative to the optimistic equilibrium.

6.1.2. Endogenous price rigidity Here, I consider a distribution of the fixed cost with bounded support, $\left[0, \phi_{\max }\right]$. I choose $\mathcal{F}$ to be uniform, though the exact specification is irrelevant to the results (see below). I characterize $\chi$ numerically using the iterative algorithm of Appendix B. For a given $\zeta$, the solution method converges to a unique MPE policy rule. This policy rule is a non-linear function of the fraction of flexible price firms, $z$, but is proportional in the sticky price, $\bar{p}$. Again, the intuition is straightforward, since money growth appears in the PSE decision rules in direct proportion to $\bar{p}$. Hence, two MPE exist, indexed by expectations. 
The fraction of flexible price firms increases with inflation. I determine whether - for reasonable values of $\phi_{\max }$ - prices are fully flexible in the steady state of the pessimistic MPE (with expectations coordinated on high inflation in all periods). ${ }^{17}$

To this end, I compute the pessimistic MPE for various values of $\phi_{\max }$ and find the largest value such that the steady state displays full price flexibility. That is, I find the value - call it $\hat{\phi}_{\max }-$ such that for all fixed cost distributions with $\phi_{\max } \leq \hat{\phi}_{\max }, z=1$ in the steady state of the pessimistic MPE; for all $\mathcal{F}$ with $\phi_{\max }>\hat{\phi}_{\max }, z<1$. Hence, the shape of $\mathcal{F}$ is irrelevant for finding $\hat{\phi}_{\max }$; if all firms choose to incur the fixed cost for $\phi_{\max } \leq \hat{\phi}_{\max }$, the exact distribution of costs does not matter.

Figure 6 plots the value of $\hat{\phi}_{\max }$ for various values of $\lambda$; to facilitate comparison with empirical measures of the cost of price change, I express $\hat{\phi}_{\max }$ as a fraction of semi-annual firm revenue in the zero inflation steady state (see below). For the baseline value of $\lambda=11$, $\hat{\phi}_{\max }=8.9 \%$; i.e., as long as the cost of a single price change is less than $8.9 \%$ of semi-annual revenue, all firms choose to incur it and the steady state of the high inflation equilibrium exhibits full price flexibility. As $\lambda$ falls the cut-off value increases. For instance, when the markup is set to $25 \%(\lambda=5)$, the cut-off value is $\hat{\phi}_{\max }=16.4 \%$, and when the markup is $35 \%(\lambda=3.85), \hat{\phi}_{\max }=18.9 \% .18$

\footnotetext{
${ }^{17}$ Note that this is inherently a quantitative issue. That is, it cannot be that, for any finite value of $\phi_{\max }$, a pessimistic MPE exists with full flexibility. To see this, compare the difference in gross profits from being flexible relative to being sticky, versus the value of $\phi_{\max }$. Flexible price profits are simply the discounted two-period sum of static monopoly profit. For any future money growth rate, there is a finite lower bound on sticky price profits: a firm can always set its two-period price as an optimal markup over future marginal cost, and earn static monopoly profit in the second period of its price contract. The worst that can happen is that the firm's relative price is so high in period one that it generates zero demand and earns zero profit. Hence, the difference between flexible and sticky price profits is bounded. So as long as the maximal fixed cost is greater than this bounded difference, full price flexibility cannot be an equilibrium.

${ }^{18}$ To express $\hat{\phi}_{\max }$ as a fraction of revenue in the high inflation MPE steady state (as opposed to the zero inflation steady state), we must distinguish between flexible and sticky price firms. As a fraction of flexible price firm revenue, the values of $\hat{\phi}_{\max }$ are numerically identical to those reported in Figure 6 . This is because flexible price firms price as a markup over marginal cost in each period, just as all firms do with zero inflation. However, as a fraction of sticky price firm revenue, $\hat{\phi}_{\max }$ is much larger. This is because sticky
} 
To understand the relationship between $\hat{\phi}_{\max }$ and $\lambda$, note that as $\lambda$ decreases, so too does the strength of the strategic complementarity: intermediate goods become less substitutable, so a firm's optimal price becomes less sensitive to others' prices. For a pessimistic MPE to exist, it must exist at higher levels of money growth and inflation. At higher inflation, the greater is the benefit to choosing flexibility, and the greater is the degree of flexibility for a given fixed cost distribution. As $\lambda$ decreases, the range of $\phi_{\max }$ values for which pessimistic MPE displays full price flexibility increases.

Recall that the fixed cost, $\phi$, corresponds to the firm's incremental cost of one additional price change. As such, the magnitude of $\hat{\phi}_{\max }$ values in Figure 6 is large. It is much larger than those used in monetary business cycle models with state-dependent pricing. For instance, Dotsey et al. (1999) consider a value of $\phi_{\max }$ equivalent to $1.5 \%$ of semi-annual steady state firm revenue, while Devereux and Siu (2007) consider a value of $2.85 \%$.

More importantly, the size of $\hat{\phi}_{\max }$ is much larger than direct measures of the cost of a single price change. Zbaracki et al. (2004) is the leading study. They track the price-setting process of a multi-product, machine-parts manufacturing firm during the late 1990s, and quantify all costs associated with the issuance of the firm's price list: managerial (information processing, decision making), customer (communication, renegotiation), and physical 'menu' costs. At a semi-annual frequency, this comes to $2.5 \%$ of the firm's revenue. ${ }^{19}$

It is obviously difficult to extrapolate based upon this single observation. For instance, it could be argued that Zbaracki et al.'s measure generates downward bias for inference of $\phi_{\max }$, due to selection: by necessity, they study a firm that is willing to make price revisions during a period of low inflation. It is also easy to argue for upward bias. During price firms set a price that is very close to an optimal markup over second-period marginal cost (see the discussion in Subsection 4.2). With high inflation, this implies that first-period revenues are much smaller than in the second. Averaging across periods of the price contract, $\hat{\phi}_{\max }=16.6 \%$ of semi-annual revenue when $\lambda=11, \hat{\phi}_{\max }=27.8 \%$ when $\lambda=5$, and $\hat{\phi}_{\max }=30.9 \%$ when $\lambda=3.85$.

${ }^{19}$ Moreover, note that the range of markups displayed in Figure 6 correspond to those for manufacturing and durable goods manufacturing estimated by Basu and Fernald (1997). As such, Zbaracki et al.'s measure (from a manufacturing firm) is well-suited for the purpose of comparison with the model's predictions for the plotted $\lambda$ values. 
periods of high inflation, it is likely that many of the tasks documented by Zbaracki et al. (market research, sales trips made expressly to communicate new prices to customers, printing of price lists) would be made routine, less costly, or altogether eliminated. For instance, it is easy to imagine that sales trips made to communicate price changes would be eliminated or reduced during such periods, and these account for about $35 \%$ of Zbaracki et al.'s documented total cost. Hence, the relevant cost of a single price change, as it pertains to high inflation expectation traps, may be much smaller.

Nonetheless, the model's results for the size of $\hat{\phi}_{\max }$ are multiple times greater than the calibrated and measured values discussed here. Hence, it is likely that for any reasonable magnitude of $\phi_{\max }$, prices are fully flexible in the high inflation equilibrium.

Real output is actually higher in the pessimistic MPE than in the optimistic one. In the optimistic equilibrium, prices are less than fully flexible, and output is lower than in the zero inflation first-best. But because prices are fully flexible in the pessimistic case, output is identical to that of the zero inflation equilibrium. Hence, the predictions for real outcomes are opposite to those from the model with exogenous price rigidity. This belies the interpretation of pessimism as periods of stagflation.

The results to this point correspond to the case in which expectations are coordinated on the pessimistic equilibrium occurring in all periods. Analytical results for the case in which agents expect low inflation to occur in only some periods are not available. However, in numerical experiments I find that, while the quantitative differences are small, equilibria that feature fluctuations between optimism and pessimism are more likely to display full flexibility (in the periods of high inflation).

To see this, suppose expectations are coordinated on high inflation occurring between dates $t$ and $t+1$, and consider two cases. In Case 1, agents expect high inflation in all subsequent periods (the case of constant expectations coordination studied up to this point). In Case 2, agents expect low inflation in all subsequent periods (so that expectations are coordinated on high inflation only at date $t$ ). Quantitatively, I find that differences in future expectations coordination have little influence on optimal policy at date $t$ (i.e., the MPE value of $X_{t}$ ). Instead, the only appreciable difference is in the strategic complementarity in 
price setting at date $t$ : it is weaker in Case 2 than in Case 1.

This can be seen (at least, qualitatively) in Figure 3. The best response function when agents expect low inflation in all subsequent periods is flatter than when agents expect high inflation. In order for current pessimistic expectations to be rationalized, equilibrium in Case 2 involves higher prices set at date $t$, and higher inflation between dates $t$ and $t+1$, compared to Case 1. Higher inflation implies that more firms choose flexibility for a given distribution of fixed costs.

Finally, note that the same would hold if agents expect fluctuations between low and high inflation in subsequent periods: in such cases, the best response function would lie between the solid and dashed lines in Figure 3, and involve greater price flexibility compared to the case of constant pessimistic expectations. Hence, MPE in which high inflation occurs only occasionally features larger values of $\hat{\phi}_{\max }$ than when high inflation occurs in all periods. Again, I find this difference to be quantitatively small. Nonetheless, it implies that for reasonable values of $\phi_{\max }$, all equilibria with high inflation in at least one period feature full price flexibility in those periods.

\subsection{Allowing for a Discontinuity in the Policy Rule}

When the MA inherits no sticky prices, money growth has no real effect and the MA is indifferent between all values of $X$. This indifference opens up the possibility for a rich set of pessimistic MPE. Since the principal objective is to demonstrate the fragility of high inflation equilibria, I provide a brief description here, with detailed analysis in Appendix C.

Consider the following discontinuous policy rule:

$$
\hat{\chi}(\bar{p}, z ; \zeta)=\left\{\begin{array}{cc}
\chi(\bar{p}, z ; \zeta) & \text { for all } \bar{p} \text { and } z<1 \\
\hat{X} & \text { for all } \bar{p} \text { and } z=1
\end{array}\right.
$$

where $\chi(\bar{p}, z ; \zeta)$ is the differentiable MPE policy rule of Subsection 6.1 and $\hat{X} \geq \beta$. Obviously this rule is optimal for the MA: for all $z<1$, this rule coincides with the original MPE rule; at $z=1$, any value of $\hat{X}$ is optimal by indifference.

To ensure this is an MPE policy rule, all that needs to be checked is that private sector 
best responses constitute equilibrium behavior. For $z<1$, rule (7) coincides with the original MPE rule, so P and Z given by (4) and (5) are optimal by definition. At $z=1$, pricing decisions are independent of current money growth. To ensure equilibrium, what needs to be checked is that all firms that chose flexibility in the previous period under the original policy rule continue to do so under rule (7); it must be that at $z=1$, no firm that chose flexibility finds it profitable to deviate to stickiness.

Since firms are differentiated only by their fixed cost, it suffices to consider the firm with the highest fixed cost, $\phi_{i}=\phi_{\max }$. The profitability of this deviation depends on the value of $\hat{X}$. For example, it cannot be that $\hat{X}=1$. With zero money growth, a firm could set a sticky price as an optimal markup over marginal cost - which is constant across periods and earn gross profits identical to those under flexible prices. Since this saves on the fixed cost, any firm would deviate to being sticky. For rule (7) to constitute an MPE policy rule, $\hat{X}$ must be large enough to ensure that the $\phi_{i}=\phi_{\max }$ firm continues to choose flexibility.

The MA's indifference at full flexibility also allows for mixed strategy policy rules. For instance, it is possible that when $z=1$, the MA generates positive money growth, $\hat{X}_{\delta}>1$, with probability $\delta<1$, and zero money growth otherwise. For this to constitute an MPE, the mixing probability must be sufficiently large. Let $\delta^{\text {min }}$ denote the smallest feasible mixing probability. Then for each $\delta \geq \delta^{\mathrm{min}}$, there is a smallest feasible money growth rate - call this $\hat{X}_{\delta}^{\min }$ - ensuring that no firm deviates from flexibility to stickiness. The characterizations of $\delta^{\mathrm{min}}$ and $\hat{X}_{\delta}^{\min }$ are in Appendix C. Here I summarize as follows:

Proposition 5 Let $\delta \in\left[\delta^{\mathrm{min}}, 1\right]$, where $\delta^{\mathrm{min}}$ is defined in (12). Then for $\hat{X}_{\delta} \in\left[\hat{X}_{\delta}^{\min }, \infty\right)$, the discontinuous, mixed strategy policy rule (11) is an MPE policy rule.

This makes it clear that pessimistic MPE can differ drastically across exogenous and endogenous price rigidity models. With exogenous price rigidity, pessimism is reflected in a unique, high value of inflation. But with endogenous rigidity, a continuum of inflation rates can occur. Finally, note that across all of these pessimistic MPE, real outcomes are identical to the case with a differentiable policy rule; the only difference is in inflation rates. 


\section{A MODEL WITH UNIQUE EQUILIBRIUM}

In the simplified model presented above, monetary policy affects real variables only when some prices are sticky. When prices are fully flexible, the MA is indifferent between all values of $X$. Here, I consider a perturbation to the model to break the MA's indifference. I introduce a non-zero cost of inflation that is present even when prices are fully flexible.

In particular, suppose there is a resource cost of money creation, $g=\varepsilon|X-1|$, where $\varepsilon>0$ can be arbitrarily small. Printing (or shredding) money is costly in terms of final goods. The MA finances money creation via lump-sum taxation, so that the MA's budget constraint is:

$$
T_{t}=M_{t}-M_{t-1}-\theta_{t-1}\left(W_{t-1} h_{t-1}+\int_{0}^{1} \Pi_{i, t-1} d i\right)-P_{t-1} g_{t-1}, \quad \forall t .
$$

The modified model's aggregate resource constraint is now:

$$
c+g=y \text {. }
$$

The rest of the model description is identical to Section 2. Apart from its effect via sticky prices, $X$ has a direct effect on the fraction of output available for consumption.

This modification has two effects. First, it implies that MPE cannot exist with full flexibility. When prices are fully flexible, the cost-benefit trade-off due to price rigidity is eliminated; the maximizing MA sets $X=1$ to minimize printing costs. This strict preference for zero money growth at full flexibility introduces an obvious deviation for firms choosing flexibility. Suppose $z=1$ so that $X=1$. Given zero money growth, a firm considering a deviation to stickiness would set a sticky price as a markup over constant current and future marginal cost. The firm would earn identical gross profits by choosing stickiness relative to flexibility, but without incurring the fixed cost. Hence, any firm would deviate to stickiness, meaning that $z \neq 1$. No MPE exists with fully flexible prices.

Second, the modification changes the nature of the inflation trade-off when $z \neq 1$. The marginal benefit of unexpected inflation is unchanged. However, the marginal cost of inflation is now greater due to the additional resource cost of money creation. Hence, for 
any value of the MA state, $s$, optimal money growth is lower; the new policy rule lies everywhere below that of the simplified model. This weakens the strategic complementarity in price setting, and thus flattens out the best response function of sticky price firms (see Subsection 4.1). Hence, if a pessimistic equilibrium were to exist, it must do so at a higher rate of inflation. But higher inflation simply reinforces the likelihood that all firms choose flexibility, and as discussed above, MPE cannot exist with fully flexible prices.

The analysis of Section 6 indicates that in the simplified model, for reasonable specifications of the fixed cost of price change, prices are fully flexible in the pessimistic MPE. Including a cost of inflation independent of rigid prices weakens the strategic complementarity in price setting. Pessimistic equilibria do not exist, and moreover, do not exist for a larger range of maximal fixed costs relative to the results of Section 6. For reasonable quantitative specifications, the modified model predicts a unique low inflation MPE.

\subsection{Discussion}

There are many ways to introduce a cost of inflation that is present with fully flexible prices, without changing the nature of the results. I discuss two possibilities. First, the cashin-advance model considered here adopts Lucas' (1982) timing of events within a period. Hence, any 'money demand' distortion is due to expected future inflation, which cannot be influenced by the MA under discretion. But in a model with Svensson's (1985) timing, current inflation is costly since households use previously accumulated cash to conduct transactions. This type of portfolio rigidity is unrelated to price rigidity. Hence, Svensson's timing would make current inflation costly even with flexible prices (for analysis of this cost in the context of monetary discretion, see Albanesi et al., 2001 and 2003).

A second way to modify the model is to change the timing of pricing decisions to more closely resemble a state-dependent pricing (SDP) model. In Section 2, firms make their pricing decision before the realization of future inflation, i.e., in the first period of the twoperiod Taylor contract. In an SDP interpretation, the decision is made after observing 
future inflation, i.e., in the second period. ${ }^{20}$ Given perfect foresight, firms in the SDP version know ex ante whether they will be changing their price ex post and set first period prices accordingly. Hence, analysis of the two versions is virtually identical when $z<1$.

But a critical difference arises when $z=1$, precisely because the firm's decision to incur the fixed cost is made ex post. Now, the MA's choice of money growth has a direct impact on the fraction of labor resources devoted to price change. Suppose all firms expect high inflation and set prices anticipating that they will be resetting them in the next period. If all firms are resetting prices, the MA's influence via rigid prices is inoperative; the MA chooses $X=1$ to eliminate labor costs of price change. Clearly, this is susceptible to the same deviation on the part of firms as before. Expectations of high inflation cannot be validated, so that self-fulfilling pessimistic MPE cannot exist for plausible fixed costs.

Finally, this analysis suggests that the fragility of expectation traps relying on sticky prices is not limited to the framework studied here. Consider the fully state-dependent pricing model of Dotsey et al. (1999) in which all price changes are costly. Again, the fraction of flexible prices is endogenous. With SDP, the number of past prices or 'vintages' at any point in time is endogenous, while in the current model the number of past vintages is assumed to be one. Crucially, I find that in high inflation settings, all firms prefer to set flexible prices as opposed to maintaining a price that has been eroded by one period of inflation. Clearly, no firm would prefer to charge a price eroded by multiple periods of inflation, so allowing for fully SDP is not likely to alter the nature of the results.

\section{CONCLUSION}

In this paper I characterize time consistent equilibrium in a model with monetary discretion and an endogenously determined degree of price rigidity. The endogeneity is introduced by allowing firms to determine their frequency of price change; more frequent price change

\footnotetext{
${ }^{20}$ See Devereux and Siu (2007). Though more familiar to the sticky price literature, the SDP version is notationally burdensome, complicating exposition. One needs to define an additional variable, $\kappa^{\prime}$, which measures the current period's expected fraction of firms that choose price flexibility in the following period. Equilibrium requires $\kappa^{\prime}=z^{\prime}$. Details are available upon request.
} 
involves incurring a fixed cost.

When welfare costs of inflation are present only with sticky prices, there exist two time consistent equilibria: an optimistic equilibrium with low inflation, and a pessimistic equilibrium with high inflation. This is in keeping with previous studies that assume exogenously rigid prices. But for quantitatively reasonable specifications of the fixed cost, the pessimistic equilibrium displays full price flexibility. When an arbitrarily small cost of inflation exists independent of rigid prices, the pessimistic equilibrium is eliminated, and time consistent equilibrium is unique.

Finally, though attention has been restricted to Markov perfect equilibrium, the nature of the results is likely to extend to environments in which the monetary authority's reputation matters. This is because the fragility of pessimistic equilibrium is due to optimizing behavior of private sector agents. Any proposed history of events that entails expectations of high inflation will result in firms opting for flexible as opposed to sticky prices. Again, this eliminates the monetary authority's welfare trade-off in inflation due to price rigidity, leading to the arguments considered here. ${ }^{21}$ Simply put, it seems problematic to formulate a model explaining high inflation equilibria based on sticky prices since, quantitatively, firms would choose not to charge sticky prices.

\footnotetext{
${ }^{21} \mathrm{An}$ interesting open question is the characterization of sustainable equilibrium with endogenous price rigidity. In particular, the possibility that prices cease to be sticky for sufficiently high inflation can limit the severity of the worst sustainable equilibrium. Hence, the conditions under which first-best monetary policies can be sustained by trigger strategies may differ under endogenous and exogenous price rigidity.
} 


\section{APPENDIX A}

Figures 3 through 5 are constructed as follows. Given a policy rule, $\chi$, I calculate the steady state corresponding to PSE when $X \equiv \chi(\bar{p})$ for a given $\zeta$. Fix a value of $\zeta$. The PS state is set to the corresponding steady state value, $(\bar{p}, z, X)=\left(\bar{p}_{s s}, z_{s s}, \chi\left(\bar{p}_{s s}\right)\right)$. I then consider a range of prices for firms setting a two-period price. For each of these sticky prices, $\bar{p}_{j}^{\prime}$, the best response, $\bar{p}_{i}^{\prime}$, is given by:

$$
\bar{p}_{i}^{\prime} \equiv f\left(\bar{p}_{j}^{\prime}, z^{\prime} ; \bar{p}, z, X ; \chi\right)=\hat{\lambda} \psi\left[\left(1-\gamma\left(\bar{p}_{j}^{\prime}, z^{\prime} ; \bar{p}, z, X ; \chi\right)\right)+\gamma\left(\bar{p}_{j}^{\prime}, z^{\prime} ; \bar{p}, z, X ; \chi\right) \chi\left(\bar{p}_{j}^{\prime}\right)\right] .
$$

The relative weight on current versus future marginal cost accounts for the fact that some firms choose flexibility:

$$
\gamma\left(\bar{p}_{j}^{\prime}, z^{\prime} ; \bar{p}, z, X ; \chi\right)=p^{\lambda-1} /\left(p^{\lambda-1}+\beta p^{\prime \lambda-1} \chi\left(\bar{p}_{j}^{\prime}\right)^{\lambda-1}\right),
$$

where

$$
\begin{aligned}
p^{\lambda-1} & =\left\{\left[(1-z)(\bar{p} / X)^{1-\lambda}+\left(1-z^{\prime}\right) \bar{p}_{j}^{1-\lambda}+\left(z+z^{\prime}\right) \tilde{p}^{1-\lambda}\right] / 2\right\}^{-1}, \\
p^{\prime \lambda-1} & =\left\{\left[\left(1-z^{\prime}\right)\left(\bar{p}_{j}^{\prime} / \chi\left(\bar{p}_{j}^{\prime}\right)\right)^{1-\lambda}+\left(1-z^{\prime \prime}\right) \bar{p}^{\prime \prime 1-\lambda}+\left(z^{\prime}+z^{\prime \prime}\right) \tilde{p}^{1-\lambda}\right] / 2\right\}^{-1} .
\end{aligned}
$$

Here, $\tilde{p}=\tilde{p}^{\prime}=\hat{\lambda} \psi$, and $\bar{p}^{\prime \prime}=\mathrm{P}\left(\bar{p}_{j}^{\prime}, z^{\prime}, \chi\left(\bar{p}_{j}^{\prime}\right) ; \chi, \zeta\right)$ and $z^{\prime \prime}=\mathrm{Z}\left(\bar{p}_{j}^{\prime}, z^{\prime}, \chi\left(\bar{p}_{j}^{\prime}\right) ; \chi, \zeta\right)$ are derived from the PSE decision rules. Determining $\bar{p}^{\prime \prime}$ and $z^{\prime \prime}$ requires calculating $\bar{p}^{\prime \prime \prime}, z^{\prime \prime \prime}$, and so on; these are also derived using $\mathrm{P}$ and $\mathrm{Z}$.

For each $\bar{p}_{j}^{\prime}$, I find $z^{\prime}$ as the value that satisfies:

$$
\begin{aligned}
& p^{\lambda-1}(\tilde{p}-\psi) / \tilde{p}^{\lambda}+\beta\left[p^{\prime \lambda-1}(\tilde{p}-\psi) / \tilde{p}^{\lambda}-\psi \mathcal{F}^{-1}\left(z^{\prime}\right)\right]= \\
& p^{\lambda-1}\left(\bar{p}_{j}^{\prime}-\psi\right) / \bar{p}_{j}^{\prime \lambda}+\beta p^{\prime \lambda-1}\left(\chi\left(\bar{p}_{j}^{\prime}\right) / \bar{p}_{j}^{\prime}\right)^{\lambda}\left(\bar{p}_{j}^{\prime} / \chi\left(\bar{p}_{j}^{\prime}\right)-\psi\right) .
\end{aligned}
$$

This is plotted in the bottom row of Figure 5. Using this value of $z^{\prime}$, I calculate $\gamma$, and the best response price, $\bar{p}_{i}^{\prime}$. In Figures 3 and $4, z=0$, and determining $z^{\prime}$ is not necessary.

\section{APPENDIX B}

The solution algorithm builds on a modified version of the MPE definition of Section 5 . This modification is discussed in Klein et al. (2006). Consider the following statement of 
the MA's problem:

$$
\max _{\bar{p}^{\prime}, z^{\prime}, X}\left[U(s, X ; \chi, \zeta)+\beta V\left(\bar{p}^{\prime}, z^{\prime} ; \zeta\right)\right]
$$

subject to

$$
\begin{gathered}
\mathcal{M} \equiv\left(p^{\lambda-1}+\beta p^{\prime \lambda-1} X^{\prime \lambda-1}\right) \bar{p}^{\prime}-\hat{\lambda} \psi\left(p^{\lambda-1}+\beta p^{\prime \lambda-1} X^{\prime \lambda}\right)=0, \\
\mathcal{N} \equiv\left(p^{\lambda-1}+\beta p^{\prime \lambda-1}\right)(\tilde{p}-\psi) / \tilde{p}^{\lambda}-\beta \psi \mathcal{F}^{-1}\left(z^{\prime}\right)- \\
{\left[p^{\lambda-1}\left(\bar{p}^{\prime}-\psi\right)+\beta p^{\prime \lambda-1} X^{\prime \lambda}\left(\bar{p}^{\prime} / X^{\prime}-\psi\right)\right] / \bar{p}^{\prime \lambda} \geq 0,}
\end{gathered}
$$

given $\zeta$, for all $s=(\bar{p}, z) \in \sigma$, with $\mathcal{N}=0$ whenever $\mathcal{F}^{-1}\left(z^{\prime}\right)<\varphi_{\max }$. Here, $p=p(s, X ; \chi, \zeta)$ and $p^{\prime}=p\left(s^{\prime}, X^{\prime} ; \chi, \zeta\right)$ are current and future normalized price levels given by equation (1), $X^{\prime}=\chi\left(s^{\prime}\right), s^{\prime}=\left(\bar{p}^{\prime}, z^{\prime}\right)$, and $\tilde{p}=\hat{\lambda} \psi$. Finally, $\bar{p}^{\prime \prime}=\tilde{\mathrm{P}}\left(s^{\prime} ; \chi, \zeta\right)$ and $z^{\prime \prime}=\tilde{\mathrm{Z}}\left(s^{\prime} ; \chi, \zeta\right)$ are one-period ahead pricing decisions taking as given that future money growth is given by $\chi\left(s^{\prime}\right)$; that is, $\tilde{\mathrm{P}}(s ; \chi, \zeta) \equiv \mathrm{P}(s, \chi(s) ; \chi, \zeta)$ and $\tilde{\mathrm{Z}}(s ; \chi, \zeta) \equiv \mathrm{Z}(s, \chi(s) ; \chi, \zeta)$. MPE requires that the maximizing value of $X$ for all $s$ coincides with $\chi(s ; \zeta)$. Furthermore, the solution to problem $(8)$ coincides with $V(s ; \zeta)$. This formulation represents a computational saving relative to Definition 3 as the dimension of the pricing decisions is reduced by one.

The generalized Euler equation (GEE) for problem (8) can be derived as follows. Let $\mu$ be the Lagrange multiplier associated with constraint $\mathcal{M}$, and $\nu$ be the multiplier on constraint $\mathcal{N}$. At an interior solution, constraints $\mathcal{M}$ and $\mathcal{N}$ must be satisfied with equality, and the FONCs can be rearranged to get:

$$
U_{c} c_{X}+U_{h} h_{X}+\mu \mathcal{M}_{X}+\nu \mathcal{N}_{X}=0
$$

where

$$
\begin{gathered}
\mu=-\frac{U_{c} c_{\bar{p}^{\prime}}+U_{h} h_{\bar{p}^{\prime}}+\beta V_{\bar{p}}^{\prime}-\mathcal{N}_{\bar{p}^{\prime}}\left(U_{c} c_{z^{\prime}}+U_{h} h_{z^{\prime}}+\beta V_{z}^{\prime}\right) / \mathcal{N}_{z^{\prime}}}{\mathcal{M}_{\bar{p}^{\prime}}-\mathcal{N}_{\bar{p}^{\prime}} \mathcal{M}_{z^{\prime}} / \mathcal{N}_{z^{\prime}}} \\
\nu=-\left(U_{c} c_{z^{\prime}}+U_{h} h_{z^{\prime}}+\beta V_{z}^{\prime}+\mu \mathcal{M}_{z^{\prime}}\right) / \mathcal{N}_{z^{\prime}}
\end{gathered}
$$

Equation (9) is the GEE. It depends on derivatives of the value function via the multipliers, 
as well as derivatives of the decision rules via the derivatives of the constraints. For example:

$$
\begin{aligned}
\mathcal{M}_{z^{\prime}}=(\lambda-1)\left[p^{\lambda-2} p_{z^{\prime}}+\beta p^{\prime \lambda-2} X^{\prime \lambda-1} \Omega+\beta p^{\prime \lambda-1} X^{\prime \lambda-2} \chi_{z}^{\prime}\right]- \\
\hat{\lambda} \psi(\lambda-1)\left[p^{\lambda-2} p_{z^{\prime}}+\beta p^{\prime \lambda-2} X^{\prime \lambda} \Omega+\hat{\lambda} \beta p^{\prime \lambda-1} X^{\prime \lambda-1} \chi_{z}^{\prime}\right],
\end{aligned}
$$

where

$$
\Omega=p_{z}^{\prime}+p_{X}^{\prime} \chi_{z}^{\prime}+p_{\bar{p}^{\prime}}^{\prime} \tilde{\mathrm{P}}_{z}^{\prime}+p_{z^{\prime}}^{\prime} \tilde{\mathrm{Z}}_{z}^{\prime}
$$

and similarly for $\mathcal{M}_{\bar{p}^{\prime}}, \mathcal{N}_{z^{\prime}}$, and $\mathcal{N}_{\bar{p}^{\prime}}$.

The following iterative algorithm makes use of the GEE to solve for MPE. The method begins with an initial guess of the policy rule, $\chi^{0}(\bar{p}, z ; \zeta)$. I specify this as a tensor product of Chebychev polynomials:

$$
\chi^{0}(\bar{p}, z ; \zeta)=\sum_{i=0}^{N-1} \sum_{j=0}^{N-1} a_{i j} T_{i}(\xi(\bar{p})) T_{j}(\vartheta(z)),
$$

where $T_{i}$ is the $i$-th order Chebychev polynomial, $\xi$ is a linear function mapping a capture region of $\bar{p}$, denote this $\left[\bar{p}_{a}, \bar{p}_{b}\right]$, into the interval $[-1,+1]$, and $\vartheta$ maps $[0,1]$ into $[-1,+1]$. The size of the approximation function is given by $N$. An initial guess of the policy rule amounts to an initial guess on the vector $\left\{a_{i j}\right\}_{i, j=0}^{N-1}$. Note that $\chi^{0}$ is differentiable and satisfies the limit condition of Subsection 6.1 by construction. Starting with $\imath=0$ :

Step 1. Using $\chi^{\imath}$, solve for approximations to the decision rules, $\tilde{\mathrm{P}}$ and $\tilde{\mathrm{Z}}$, over a grid of $(\bar{p}, z)$ values, $G=\left[\bar{p}_{a}, \bar{p}_{b}\right] \times[0,1)$, for the given $\zeta$. This is done by: (a) specifying the decision rules to be of the same functional form as (10), (b) making an initial guess on the coefficient vectors, (c) solving constraints $\mathcal{M}$ and $\mathcal{N}$ for $\bar{p}^{\prime}$ and $z^{\prime}$ over $G$, and (d) using the $\bar{p}^{\prime}$ and $z^{\prime}$ solutions to iterate on the coefficient vectors until convergence. Note that $\tilde{\mathrm{P}}$ and $\tilde{\mathrm{Z}}$ are differentiable by construction. Using $\chi^{\imath}, \tilde{\mathrm{P}}$, and $\tilde{\mathrm{Z}}$, solve for $\bar{p}^{\prime}$ and $z^{\prime}$ values at $z=1$; call these $\bar{p}_{1}^{\prime}$ and $z_{1}^{\prime}$.

Step 2. Using $\chi^{\imath}, \tilde{\mathrm{P}}, \tilde{\mathrm{Z}}, \bar{p}_{1}^{\prime}$, and $z_{1}^{\prime}$, solve for approximations to the value function, $V(s ; \zeta)$, $s \in G$. This is done by: (a) computing the present discounted value of utility for each gridpoint, and (b) fitting a function of the form (10) to these points. Note that $V$ is differentiable by construction. Also solve for $V$ at $z=1$; call this $v_{1}$. 
Step 3. Using $\chi^{\imath}, \tilde{\mathrm{P}}, \tilde{\mathrm{Z}}, \bar{p}_{1}^{\prime}, z_{1}^{\prime}, V$, and $v_{1}$, solve the MA's problem (8), given $\zeta$, for $X, \bar{p}^{\prime}$, and $z^{\prime}$ over $G$. When the solution is interior $(z<1)$, it can be found by satisfying constraints $\mathcal{M}$ and $\mathcal{N}$, and the GEE (9) with equality. When the solution is at a corner $(z=1)$, it can be found by performing a more tedious line search for the maximizing value of $X$. Use the $X, \bar{p}^{\prime}$, and $z^{\prime}$ solutions to get a new guess of the policy rule, $\chi^{\imath+1}$.

Iterate on steps 1 to 3 until the coefficients on the policy rule converge. To check that the MPE policy rule is unique for a given $\zeta$, do this for several initial guesses, $\chi^{0}$. To ensure that the policy rule is proportional in $\bar{p}$, choose initial guesses that are non-linear in $\bar{p}$.

\section{APPENDIX C}

\section{C.1. Derivations for the Discontinuous Policy Rule}

Here, I characterize $\hat{X}^{\text {min }}$, the smallest admissible money growth at $z=1$, such that $(7)$ is an MPE policy rule. Consider all values of $s=(\bar{p}, z)$ such that $z^{\prime}=\mathrm{Z}(s, \chi(s) ; \chi, \zeta)=1$, where $\chi$ is the differentiable MPE policy rule of Subsection 6.1; denote these states as $\hat{\sigma} \subseteq \sigma$. Given that $X^{\prime}=\hat{X}$, flexible price profits for the $\phi_{i}=\phi_{\max }$ firm at state $\hat{s} \in \hat{\sigma}$ are given by:

$$
\tilde{\Upsilon}(\hat{s} ; \zeta) \equiv p^{\lambda-1}(\tilde{p}-\psi) / \tilde{p}^{\lambda}+\beta\left[p^{\prime \lambda-1}(\tilde{p}-\psi) / \tilde{p}^{\lambda}-\psi \phi_{\max }\right]
$$

where $\tilde{p}=\hat{\lambda} \psi$,

$$
\begin{aligned}
p^{\lambda-1} & =\left\{\left[(1-z)(\bar{p} / \hat{\chi}(\hat{s}))^{1-\lambda}+(z+1) \tilde{p}^{1-\lambda}\right] / 2\right\}^{-1} \\
p^{\prime \lambda-1} & =\left\{\left[\left(1-z^{\prime \prime}\right) \bar{p}^{\prime \prime \lambda-1}+\left(1+z^{\prime \prime}\right) \tilde{p}^{1-\lambda}\right] / 2\right\}^{-1}
\end{aligned}
$$

and $z^{\prime \prime}=\mathrm{Z}(., 1 ;$.$) and \bar{p}^{\prime \prime}=\mathrm{P}(., 1 ;$.$) are the pricing decisions given z^{\prime}=1$. Given that $z^{\prime}=1$, the decision rules $\mathrm{P}$ and $\mathrm{Z}$ are independent of the values of $\bar{p}^{\prime}$ and $X^{\prime}$. If the firm chooses to deviate by charging a sticky price, it earns profits:

$$
\bar{\Upsilon}(\hat{s}, \hat{X} ; \zeta) \equiv p^{\lambda-1}\left(\bar{p}^{\prime}-\psi\right) / \bar{p}^{\prime \lambda}+\beta p^{\prime \lambda-1}\left(\hat{X} / \bar{p}^{\prime}\right)^{\lambda}\left(\bar{p}^{\prime} / \hat{X}-\psi\right)
$$


where

$$
\bar{p}^{\prime}=\hat{\lambda} \psi\left(p^{\lambda-1}+\beta p^{\prime \lambda-1} \hat{X}^{\lambda}\right) /\left(p^{\lambda-1}+\beta p^{\prime \lambda-1} \hat{X}^{\lambda-1}\right) .
$$

In order for the deviation to be unprofitable, it must be that:

$$
\tilde{\Upsilon}(\hat{s} ; \zeta) \geq \bar{\Upsilon}(\hat{s}, \hat{X} ; \zeta)
$$

Let $\hat{X}(\hat{s} ; \zeta)^{\text {min }}$ denote the smallest $\hat{X}$ such that this holds at $\hat{s}$. This condition must hold for all $\hat{s} \in \hat{\sigma}$. Hence, in order for $\hat{\chi}$, with $\hat{\chi}(\bar{p}, 1 ; \zeta)=\hat{X}$, to constitute an MPE policy rule it must be that $\hat{X} \geq \hat{X}^{\text {min }}$, where:

$$
\hat{X}^{\min }=\max _{\hat{s} \in \hat{\sigma}}\left[\hat{X}(\hat{s} ; \zeta)^{\min }\right]
$$

\section{C.2. Derivations for the Mixed Strategy Policy Rule}

Consider policy rules of the following form:

$$
\hat{\chi}_{\delta}(\bar{p}, z ; \zeta)=\left\{\begin{array}{cc}
\chi(\bar{p}, z ; \zeta) & \text { for all } \bar{p} \text { and } z<1 \\
\hat{X}_{\delta} & \text { for all } \bar{p} \text { and } z=1 \text { with probability } \delta \\
1 & \text { for all } \bar{p} \text { and } z=1 \text { with probability } 1-\delta
\end{array}\right.
$$

where $\chi$ is the differentiable MPE policy rule of Subsection 6.1. When the MA inherits $z=1$ it generates positive money growth, $\hat{X}_{\delta}>1$, with probability $\delta$, and zero money growth otherwise. Showing that rule (11) is a MPE policy rule entails checking that at $z=1$, no firm deviates to stickiness.

Ruling out such deviations requires restricting the admissible values of $\delta$. For instance, in the neighborhood of $\delta=0$, the optimal sticky price implies negative profit when $\hat{X}_{\delta}$ is realized. Given the option, the firm would choose to shut down rather than meet demand. Hence, for $\delta$ sufficiently small, a sticky price firm finds it optimal to set a price anticipating zero money growth, and shut down when positive money growth occurs. Accounting for shutdown puts a lower bound on the set of feasible $\delta$ values.

Let $\delta^{\text {min }}$ denote the smallest admissible mixing probability such that (11) constitutes a MPE with the option of shutdown. It suffices to check that the $\phi_{i}=\phi_{\max }$ firm does not 
deviate to stickiness. Denote the states such that $z^{\prime}=\mathrm{Z}(s, \chi(s) ; \zeta)=1$ as $\hat{\sigma} \subseteq \sigma$. Since the deviating firm shuts down when $\hat{X}_{\delta}$ is realized, it is pricing only for the zero money growth state in the future and charges a price identical to the optimal flexible price, $\bar{p}^{\prime}=\tilde{p}=\hat{\lambda} \psi$. Profits from this deviation are:

$$
\Theta(\hat{s} ; \zeta) \equiv p^{\lambda-1}(\tilde{p}-\psi) / \tilde{p}^{\lambda}+\beta(1-\delta) p^{\prime \lambda-1}(\tilde{p}-\psi) / \tilde{p}^{\lambda}
$$

where $p^{\lambda-1}$ and $p^{\prime \lambda-1}$ are as given in Subsection C.1 with $\hat{\chi}(\hat{s} ; \zeta)$ replaced by $\hat{\chi}_{\delta}(\hat{s} ; \zeta), \hat{s} \in \hat{\sigma}$. To ensure that this is not profitable, it must be that $\tilde{\Upsilon}(\hat{s} ; \zeta) \geq \Theta(\hat{s} ; \zeta)$; simplifying this condition indicates that it holds whenever $\delta \geq\left(\tilde{p}^{\lambda} \phi_{\max }\right) /\left[p^{\prime \lambda-1}(\hat{\lambda}-1)\right]$. This condition is independent of $\hat{s}$ and $\hat{X}_{\delta}$. Hence, the smallest feasible mixing probability is:

$$
\delta^{\min }=\frac{\tilde{p}^{\lambda} \phi_{\max }}{p^{\prime \lambda-1}(\hat{\lambda}-1)} .
$$

For all $\delta \geq \delta^{\text {min }}$, the value of $\hat{X}_{\delta}^{\text {min }}$ is defined in an identical fashion to $\hat{X}^{\text {min }}$ above.

\section{REFERENCES}

[1] Albanesi, S., V. Chari and L. Christiano, 2001. How Severe Is the Time Inconsistency Problem in Monetary Policy? NBER Working Paper 8139.

[2] Albanesi, S., V. Chari and L. Christiano, 2003. Expectation Traps and Monetary Policy. Review of Economic Studies 70, 715-41.

[3] Ball, L., and D. Romer, 1991. Sticky Prices as Coordination Failure. American Economic Review 81, 539-52.

[4] Barro, R., and D. Gordon, 1983. A Positive Theory of Monetary Policy in a Natural Rate Model. Journal of Political Economy 91, 589-610.

[5] Barseghyan, L., and R. Di Cecio, 2007. Optimal Monetary Policy, Endogenous Sticky Prices, and Multiple Equilibria. B.E. Press Topics in Macroeconomics 7, Article 8. 
[6] Basu, S. and J. Fernald, 1997. Returns to Scale in U.S. Production: Estimates and Implications. Journal of Political Economy 105, 249-83.

[7] Chari, V., L. Christiano and M. Eichenbaum, 1998. Expectation Traps and Discretion. Journal of Economic Theory 81, 462-92.

[8] Chari, V., and P. Kehoe, 1990. Sustainable Plans. Journal of Political Economy 98, 783-802.

[9] Chari, V., P. Kehoe and E. McGrattan, 2000. Sticky Price Models of the Business Cycle: Can the Contract Multiplier Solve the Persistence Problem? Econometrica, 68, 1151-79.

[10] Christiano, L., M. Eichenbaum and C. Evans, 2005. Nominal Rigidities and the Dynamic Effects of a Shock to Monetary Policy. Journal of Political Economy 113, 1-45.

[11] Cooley, T., and G. Hansen, 1989. The Inflation Tax in a Real Business Cycle Model. American Economic Review 79, 733-48.

[12] Cooper, R., and A. John, 1988. Coordinating Coordination Failures in Keynesian Models. Quarterly Journal of Economics 103, 441-63.

[13] Devereux, M., and H. Siu, 2007. State Dependent Pricing and Business Cycle Asymmetries. International Economic Review 48, 281-310.

[14] Dotsey, M., R. King and A. Wolman, 1999. State-Dependent Pricing and the General Equilibrium Dynamics of Money and Output. Quarterly Journal of Economics, 655-90.

[15] Ireland, P., 1997. Sustainable Monetary Policies. Journal of Economic Dynamics and Control 22, 87-108.

[16] Ireland, P., 2000. Expectations, Credibility, and Time-Consistent Monetary Policy. Macroeconomic Dynamics 4, 448-66.

[17] King, R., and A. Wolman, 1999. What Should the Monetary Authority Do When Prices are Sticky? In: Taylor, J. (ed.), Monetary Policy Rules. Chicago University Press, Chicago, 349-98. 
[18] King, R., and A. Wolman, 2004. Monetary Discretion, Pricing Complementarity, and Dynamic Multiple Equilibria. Quarterly Journal of Economics 119, 1513-53.

[19] Klein, P., P. Krusell and J. Ríos-Rull, 2006. Time-Consistent Public Expenditures. mimeo, University of Western Ontario.

[20] Kydland, F., and E. Prescott, 1977. Rules Rather than Discretion: The Inconsistency of Optimal Plans. Journal of Political Economy 85, 473-92.

[21] Lucas, R., 1982. Interest Rates and Currency Prices in a Two-Country World. Journal of Monetary Economics 10, 335-59.

[22] Romer, D., 2001. Advanced Macroeconomics, 2nd edition. McGraw-Hill.

[23] Svensson, L., 1985. Money and Asset Prices in a Cash-in-Advance Economy. Journal of Political Economy 93, 919-44.

[24] Taylor, J., 1980. Aggregate Dynamics and Staggered Contracts. Journal of Political Economy $88,1-23$.

[25] Zbaracki, M., M. Ritson, D. Levy, S. Dutta and M. Bergen, 2004. Managerial and Customer Costs of Price Adjustment: Direct Evidence from Industrial Markets. Review of Economics and Statistics 86, 514-33. 


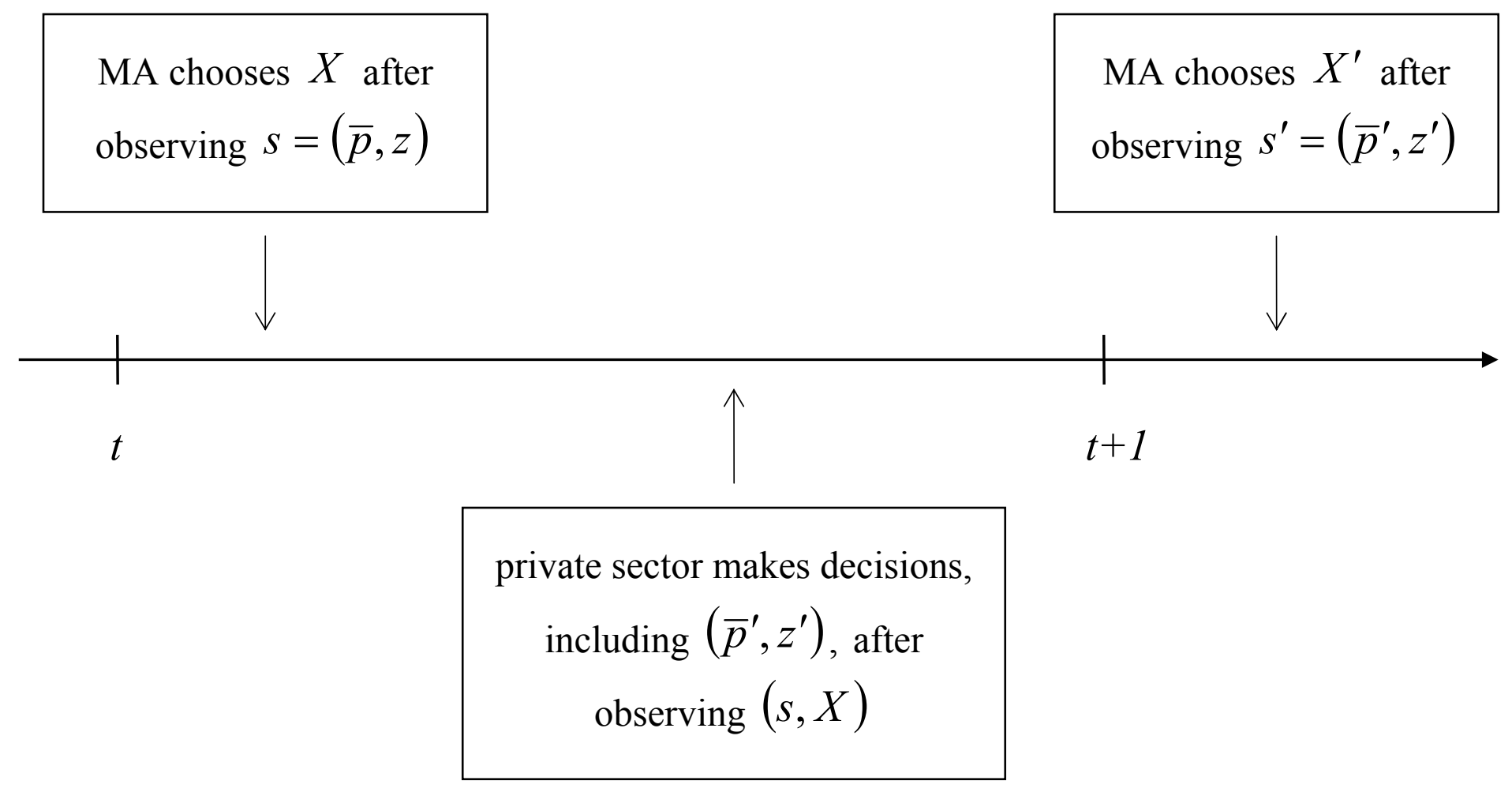

Figure 1. Timing of events within a period. 


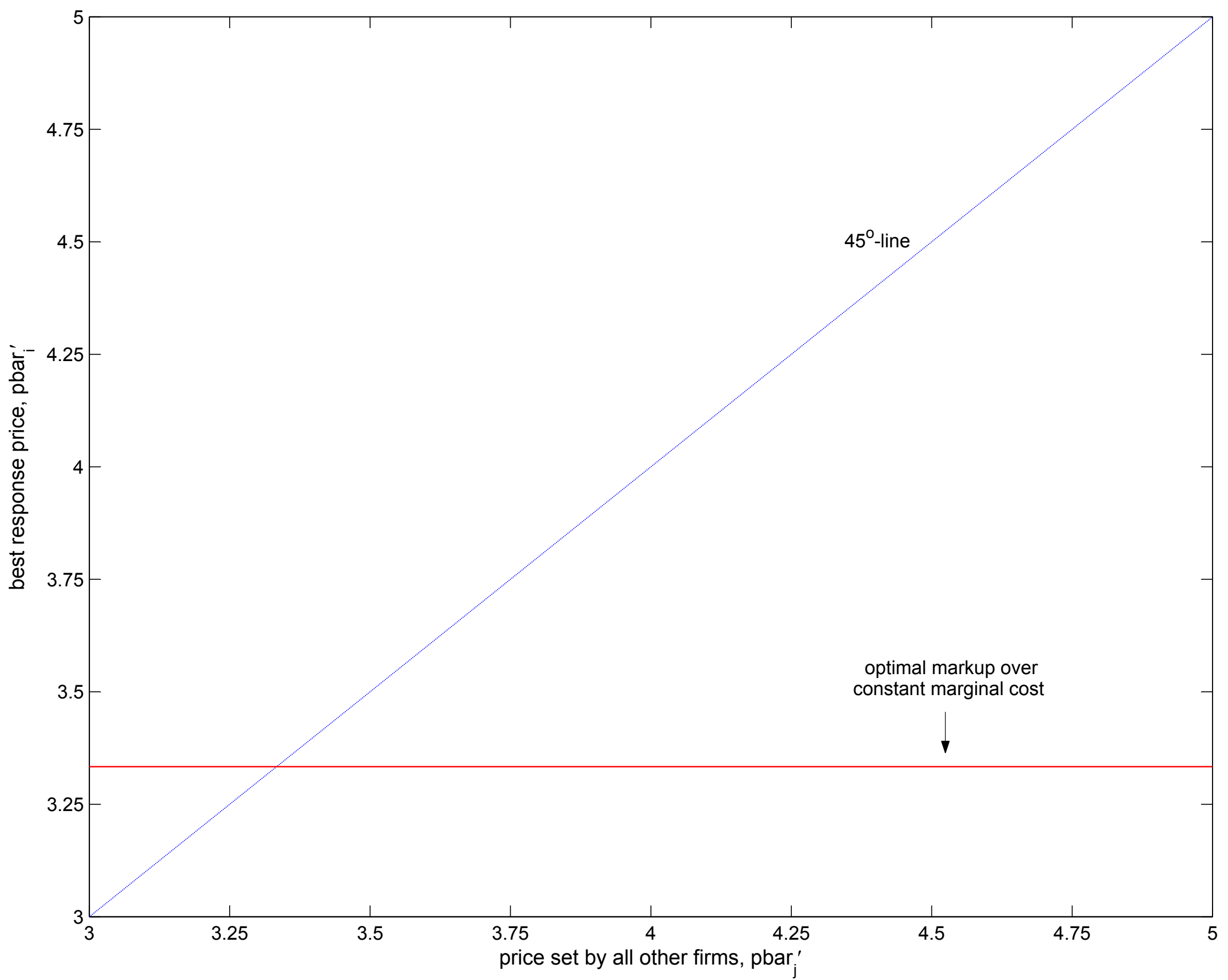

Figure 2. Best response function: zero money growth. 


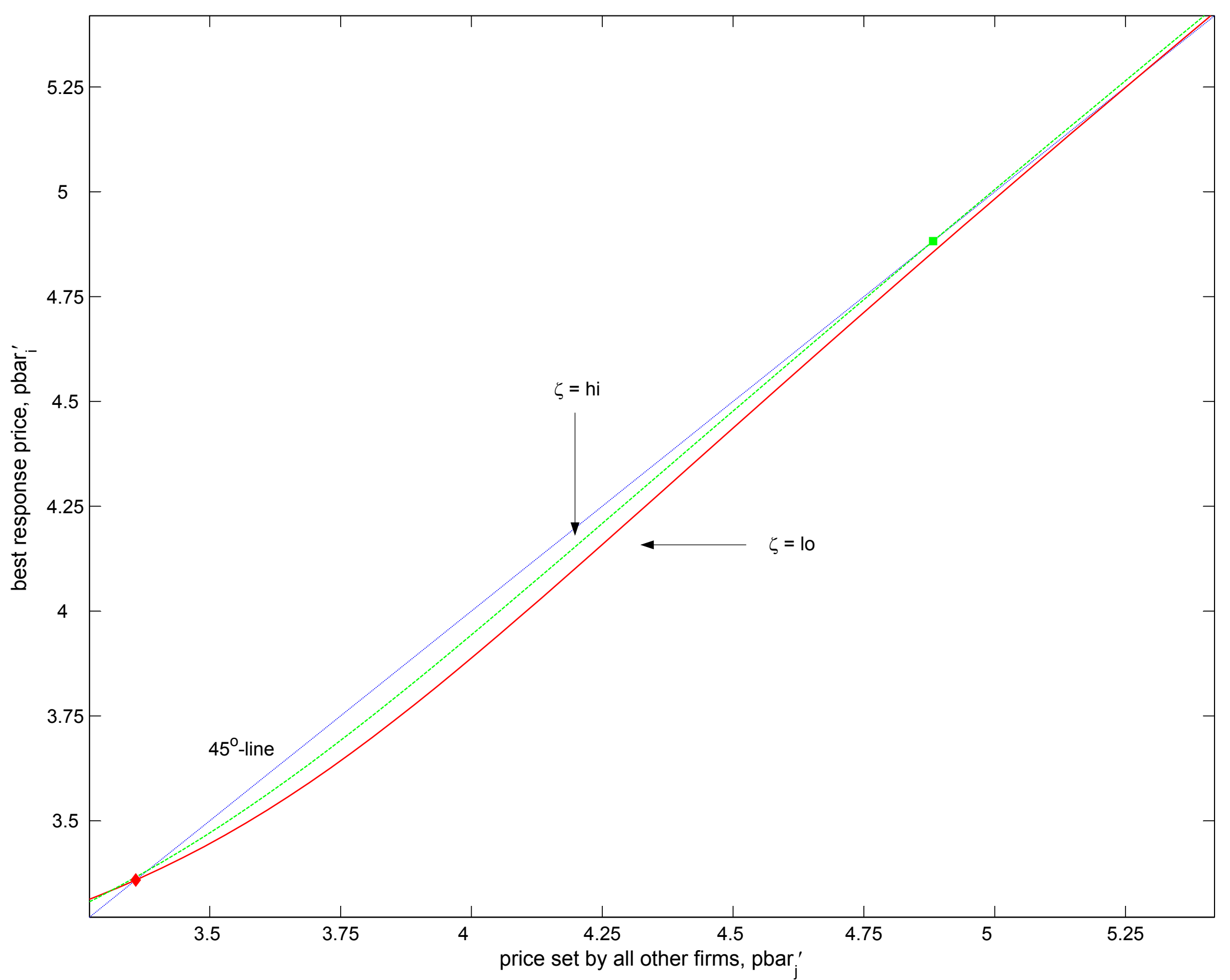

Figure 3. Best response functions: linear policy rule. Solid line: future expectations coordinated on low inflation equilibri um; dashed line: future expectations coordinated on high inflation equilibrium. 


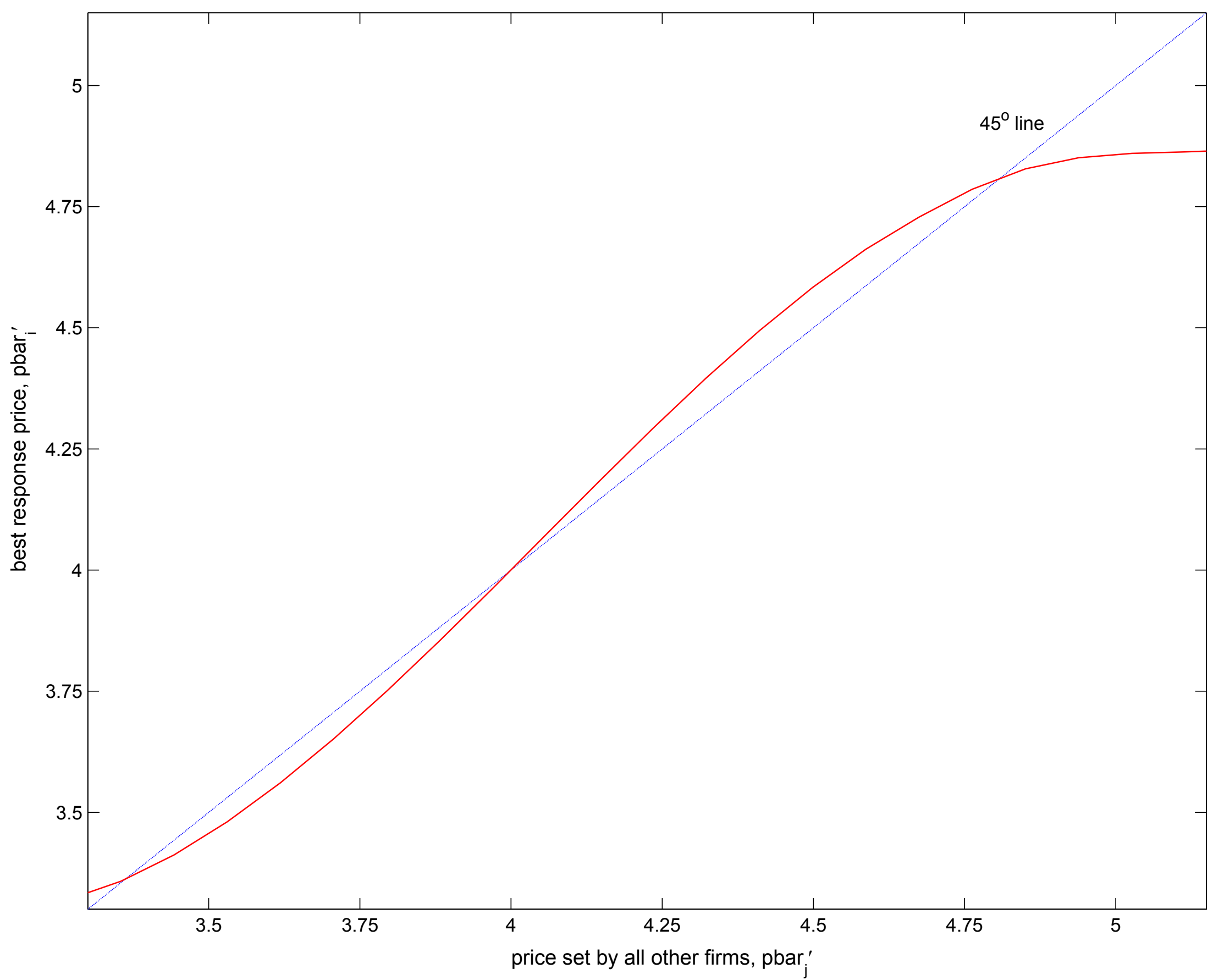

Figure 4. Best response function: non-linear policy rule. 

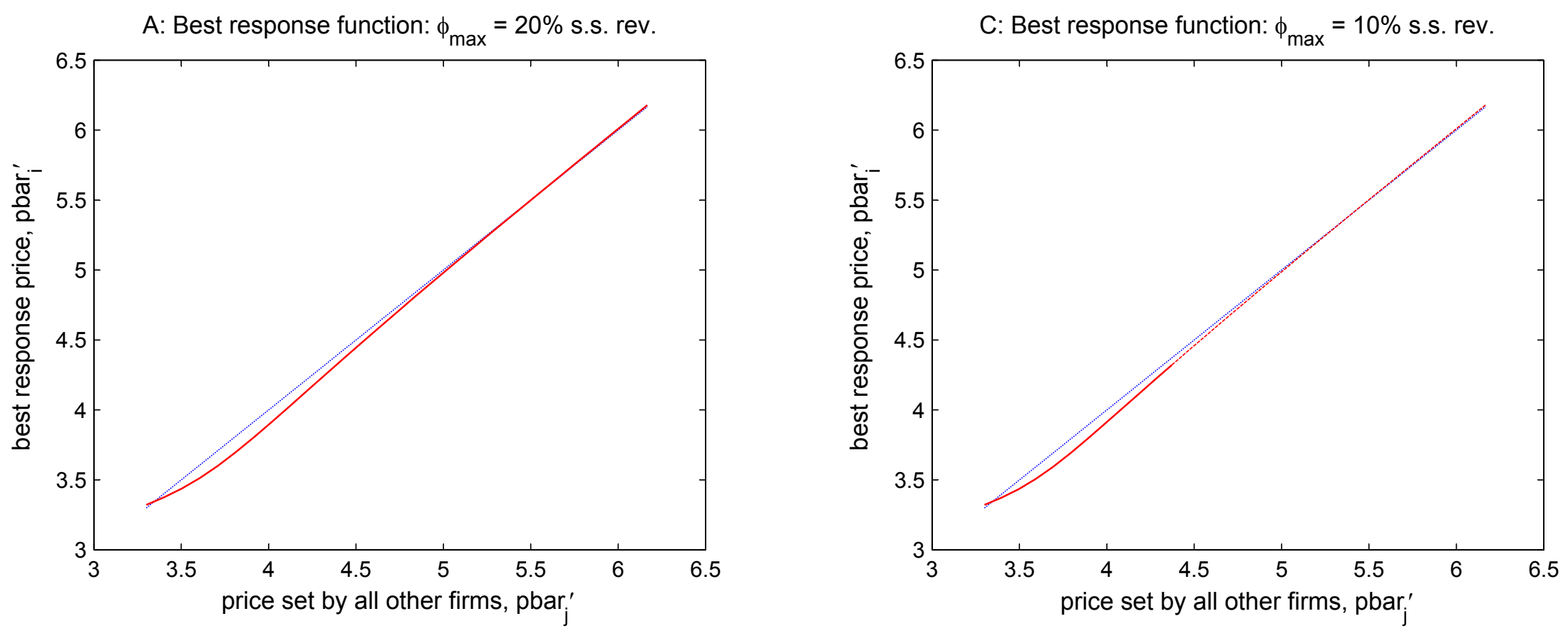

B: Degree of price flexibility: $\phi_{\max }=20 \%$ s.s. rev.

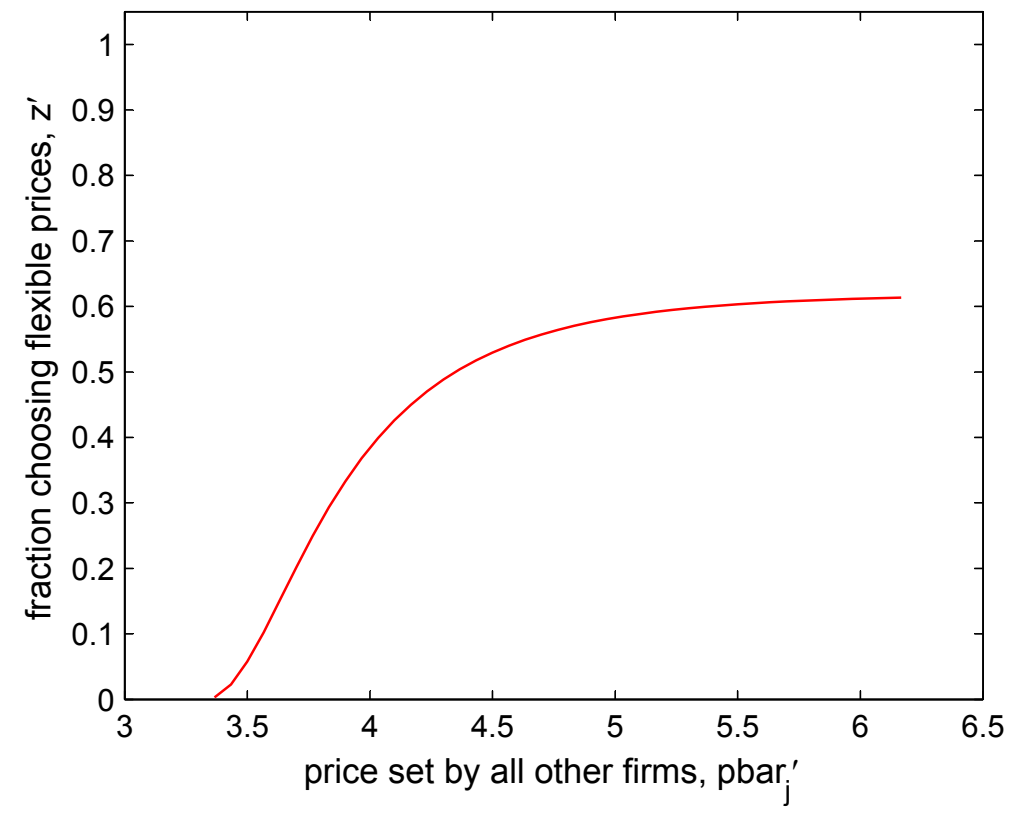

D: Degree of price flexibility: $\phi_{\max }=10 \%$ s.s. rev.

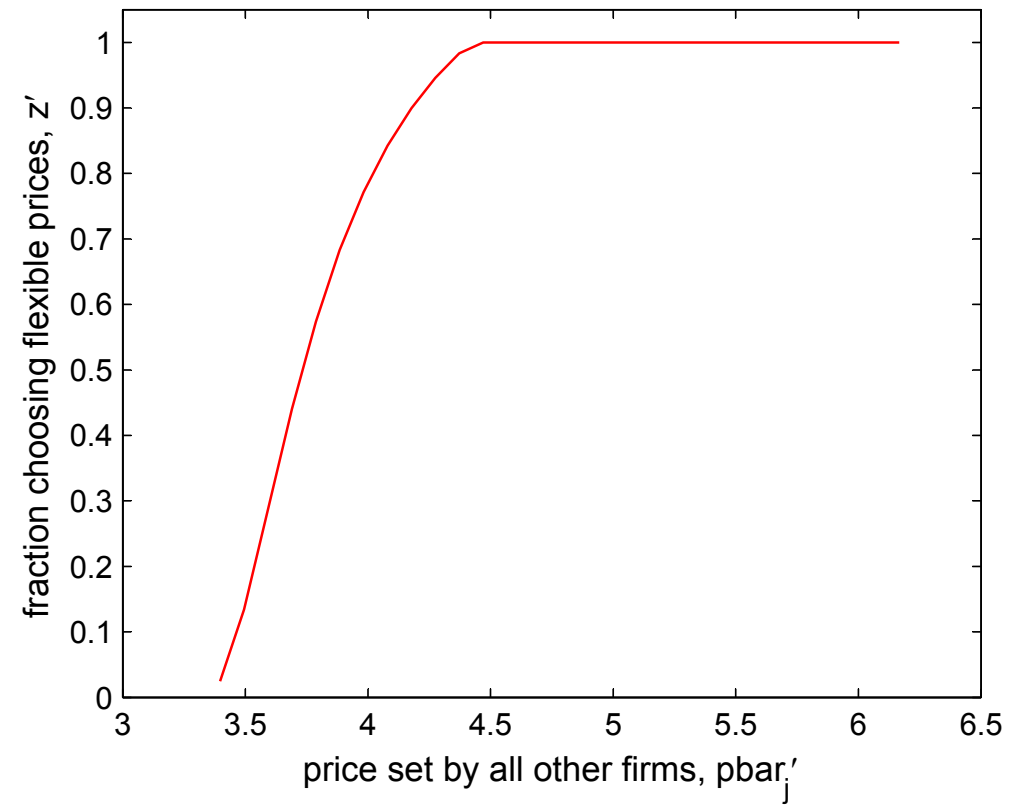

Figure 5. Best response function and fraction of firms choosing price flexibility. Left column: large maximal fixed cost. Right column: small maximal fixed cost. 


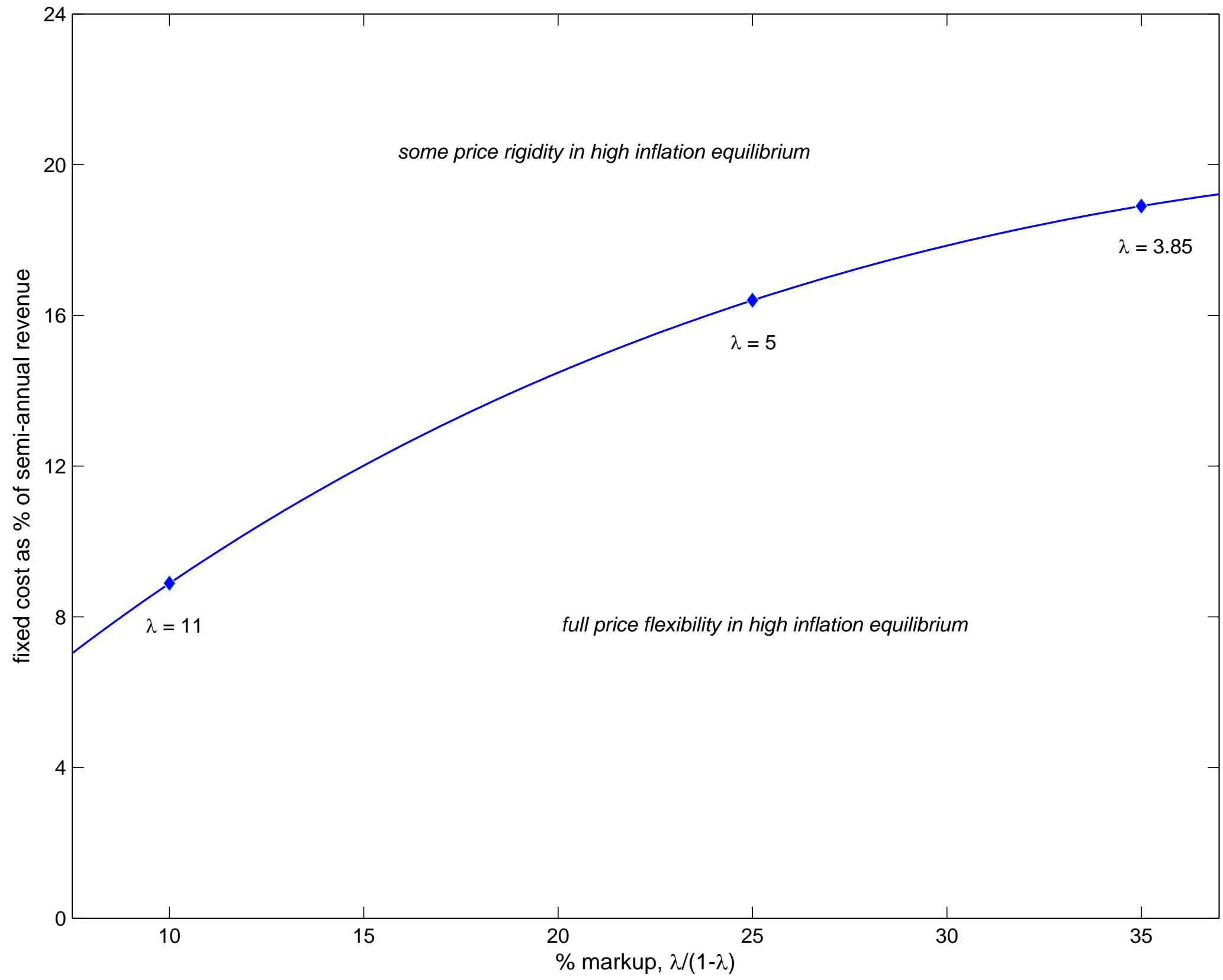

Figure 6. Maximal fixed cost such that pessimistic MPE displays full price flexibility in steady state, for various values of $\lambda$. 